\title{
Energy Optimization in Smart Urban Buildings using Bio-inspired Ant Colony Optimization
}

Fakhri Alam Khan ${ }^{1}$, Kifayat Ullah ${ }^{2}$, Atta ur Rahman ${ }^{3}$ and Sajid Anwar ${ }^{4}$

1. Department of Information \& Computer Science, King Fahd University of Petroleum \& Minerals, Dhahran, Saudi Arabia. Email:

fakhri.khan@kfupm.edu.sa

2. Centre of Excellence in IT, IMSciences, Peshawar, Pakistan. Email: sheikhkifayat248@gmail.com

3. Centre of Excellence in Data Science, IMSciences, Peshawar, Pakistan. Email: attaurrahman@imsciences.edu.pk

4. Centre of Excellence in IT, IMSciences, Peshawar, Pakistan. Email: sajid.anwar@imsciences.edu.pk

\begin{abstract}
Instead of planting new electricity generation units, there is a need to design an efficient energy management system to achieve a normalized trend of power consumption. Smart grid has been evolved as a solution, where Demand Response (DR) strategy is used to modify the nature of demand of consumer. In return, utility pay incentives to the consumer. The increasing load demand in residential area and irregular electricity load profile have encouraged us to propose an efficient Home Energy Management System (HEMS) for optimal scheduling of home appliances. In order to meet the electricity demand of the consumers, the energy consumption pattern of a consumer is maintained through scheduling the appliances in day-ahead and real-time bases. In this paper we propose a hybrid algorithm Bacterial foraging Ant colony optimization is proposed (HB-ACO) which contain both BFA and ACO properties. Primary objectives of scheduling is to shift load from On-peak hour to Off-peak hours to reduce electricity cost and peak to average ratio. A comparison of these algorithms is also presented in terms of performance parameters electricity cost, reduction of PAR and user comfort in term of waiting time. The proposed techniques are evaluated using two pricing scheme time of use and critical peak pricing. The HB-ACO shows better performance as compared to $\mathrm{ACO}$ and BFA which is evident from the simulation results Moreover the concept of coordination among home appliances is presented for real time scheduling. We consider this is knapsack problem and solve it through Ant colony optimization algorithm.
\end{abstract}


Keywords: Smart urban home, day-ahead and real-time scheduling, bacterial foraging optimization, ant colony optimization, real time pricing.

\section{INTRODUCTION}

Non-commercial sector consume a large scale world electricity globally. As population increase day by day thus the demand for electricity will increase. Research shows that major portion of world electricity, about $30 \%-40 \%$ is consumed by residential sector [1]. This is challenge to reduce the consumption of electricity. Existing grid have a lot of challenges like maintenance, reliability, and system loses. Researchers have improve the existing technology of conventional grid, thus to become it smart and dynamic. Smart grid and end user can communicate with each other to improve reliability, efficiency, and cost effectiveness. The main strategy in smart grid is Demand side management (DSM), which maintain grid stable by developing a flexible and diverse strategies. The objective of DSM is to motivate end user to optimally used electricity to reduce stress on the grid utility for continuous power supply. Early load shifting technique is Direct load control (DLC) used in DSM [2], in which utility companies disconnect certain load of consumers at short notice. This system is not frequent and not suitable for building contain a huge amount of appliances with relatively low power consumption. The most frequent technique for a load shifting management in literature is demand response (DR) [3]. In Demand Response strategy utility demand to change power consumption with respect to current price signal i.e. when price is high reduce power consumption and use more power when price is low, it will reduce monetary cost, stress on grid and as well as reduce Peak to average ratio [4]. DSM implementation need, smart meters, and smart appliances. Implementation of SG and DSM is challenging task, because we need a generic system to achieve objectives independently. Different technique and architecture are used to implement DR in smart home, because number of appliance are multiple in smart home, to minimize electricity cost and schedule home appliances in a balance away to reduce stress on the grid. Researchers in,[14]-[25] designed different architecture and algorithms for home energy management systems (HEMSs) using different pricing approaches i.e. CPP, TOU, RTP along with renewable and sustainable energy to reduce electricity cost and peak to average ratio during the day when electricity price is high. HEMS is a system using to monitor usage and flow of electricity. Some nature inspired technique are also used to solve load shifting problem. Nature is a source of inspiration from the past few decades which develop a searching algorithm to solve a complex engineering problem. These heuristic algorithm give near optimal solution to a specific problem. [26]-[34] researchers used different bio-inspired algorithm, these algorithm provide 
search space and from that search space one with optimal solution is used for scheduling different home appliances. There are many bio-inspired algorithms used for scheduling home appliances. The Authors designed a home energy management system HEM using two heuristic algorithm Harmony Search Algorithm (HSA) and Bacterial foraging optimization algorithm (BFA) [5]. On the basis of HSA and BFA authors proposed another hybrid algorithm called Hybrid Bacterial Harmony (HBH) algorithm. Authors proposed a HEMS (Home energy management system) for scheduling different home appliance on day ahead and real time basis, to reduce electricity cost, peak to average ratio, and user discomfort [6]. Authors use Genetic algorithm (GA) and Bacterial foraging optimization algorithm (BFA) and designed a Hybrid Bacterial foraging and Genetic algorithm (HBG) having both qualities. Authors proposed a hybrid GA-PSO (HGPO) algorithms using existing algorithms heuristic Genetic Algorithm (GA), Binary Particle Swarm optimization Algorithm (BPSO), Bacterial foraging optimization (BFO) [7]. Authors proposed an architecture for DSM and evaluate the performance of energy management controller using Genetic algorithm (GA), binary particle swarm optimization (BPSO) and ant colony optimization algorithm (ACO) [8]. Authors proposed a hybrid technique HGWDE technique, based on heuristics algorithms Enhanced differential Evolution (EDC) and Gray Wolf optimization (GWO) inspired from the hunting and leadership nature of wolves [9]. Real time pricing RTP and critical peal pricing are also used.

In this research work SHEM system is proposed for load shifting to reduce electricity cost and PAR, for scheduling home appliances two heuristic algorithms BFA and ACO are used. BFA provide local search and limitation having global search, for global search we use ACO because it is simple, robust, short computation time. After analyzing the performance of existing algorithms, it is require to improve search efficiency so on the basis of these algorithms we proposed a hybrid algorithm called Hybrid Bacterial Foraging and Ant Colony Optimization Algorithm HB-ACO. We use the concept of coordination among home appliances, when a user switch-off appliance the remaining time slot will be used to reschedule high priority appliances to reduce the waiting time of appliance in run time, this is a Knapsack problem and to solve problem we used ACO algorithm. Contribution of this research are follows:

1. HB-ACO: In this research we are focus on designing a hybrid optimization technique. We demonstrate the performance of existing technique. After analyzing BFA and ACO, it is observed to design a technique which can further improve search efficiency. This hybrid technique will reduce cost and PAR. 
2. Real time scheduling is a binary Knapsack problem, when a user switch-off certain load the remaining time of appliance is allocate to other preference appliance(s) by rescheduling to reduce waiting time of appliance, to solve this knapsack problem we are using ACO algorithm.

\section{LITRATURE REVIEW}

Energy management is not essential at a grid level, but it is also important to have a energy management system at user level, thus to participate in demand response program (DR) more actively. The Home energy management (HEM) system plays a vital role during optimum use of electricity. SHEM system provide an efficient service to monitor and control electricity storage, generation and consumption. Smart home contain different sensors through which different sensing data is collected from appliances, this data will communicate through HAN,s (Home area network) for real time monitoring and different operational mode are perform from personal laptop or mobile [13]. In this regard different techniques are used.

Authors in [14], proposed smart Home energy management system (SHEMS) which is based on 802.15.4 standard and ZigBee called "ZigBee Sensor Network". The proposed system divide and assign different home network task to appropriate components. It can sense various physical device and control various home appliances. The authors also proposed a new routing protocol DMPR (Disjoint Multi Path based Routing) to improve the performance of ZigBee sensor Network. In this system different sensors, video camera, and actuator are used to gain data from physical objects and humans which is very high cost. It create privacy issues and maintenance of such system is also issue. Authors proposed a three layer architecture for DSM in smart building, Admission Controller (AC) layer communicate with physical devices, Load balancing (LB) middle layer communicate between AC and DRM, and Demand Response Manager (DRM) and Load Forecaster (LF) communicate with grid and LF provide information to DRM about price signal [15]. This system handle different price signal like current peak price (CPP), Time of Use (TOU). In this system change in line capacity and energy price occur when change occur in the whole grid. Disadvantage of this system is that it will create another peak to average ratio when all the load is shift at the same time. Authors proposed a SHEMS to control home appliance, battery storage, distributed generation using approximate dynamic programming (ADR) and temporal difference learning, an approach applied for grid level storage [16]. This system enable user to purchase less electricity from grid thus to reduce electricity cost. Exact price signals i.e. Time of use price signal are used in this system. In this system when uncertain condition occur like weather this will effect PV storage so this will effect whole system, user comfort 
is did not consider in this model. Authors proposed a stochastic model for Home energy Management (HEM) by considering uncertainty of availability of EVs (Electric Vehicle) and small scale renewable energy generation to reduce electricity cost with a reasonable user satisfaction [17]. In this model dissatisfaction occur due to discharging of batteries. Researchers in [18], designed a middleware framework called Hydra, it provide communication to smart devices on $\mathrm{P} 2 \mathrm{P}$ connection. This framework provide real time data of smart devices collect through smart meter plugs for monitoring and analyzing. Mobile application is work on the top of middleware framework which show that which appliance consume how much energy, the object is recognize in image recognition server, every appliance is object ID and position. So the user is better understanding to develop a strategy to save energy and reduce cost. This system is highly cost and contain security and management issues. Authors, propose mixed-integer quadratic programming model predictive control (MPC) which have both thermal and electrical key qualities, proposed model optimally manage PEV, Thermal storage, battery storage [19]. Unsupervised occupancy prediction is used decrease cost due to user thermal comfort constraints. There is no coordination between renewable and sustainable energy. Authors in [20], design hardware for SHEMS with communication and sensing capability, and machine learning algorithm to detect human activities in a smart home to reduce electricity cost . This system will send consumer the weather information so the user can better manage their home appliances. However User comfort is ignored in this model. Authors proposed a human-centric model for the management of energy in a smart home at butler level [21]. The model sensing data from physical and cyber space to find the pattern of power usage, and know the behaviors of human beings. Authors proposed a multiagent model for smart home energy management for efficient use of energy, it communicate with energy source and smart devices in the smart home [22]. Smart appliances are the multiple agent and optimization algorithm is used for decision making of agent. Authors proposed an architecture and control algorithm for efficient manage of renewable energy in building [23]. In this article researchers proposed multi-objective (mixed integer nonlinear Programming) MINLP-based algorithm which schedule different task for the optimal use of energy in smart home [24]. Authors designed architecture and a functional module of smart HEMS. Authors also survey different renewable energy resources like solar mass thermal, and presented home appliances scheduling to reduce EC and to improve energy efficiency at grid level [25].

The aforementioned technique like MINLP, MPC, LP, are very slow convergence rate. And when appliances are large in number it cannot handle this situation. Therefore we are using heuristic algorithms because it give near optimal solution to a problem, when it is difficult to find exact solution of a problem. 
Authors, used meta-heuristic algorithms BFA and HAS and proposed HEMS and a hybrid algorithm Hybrid Bacterial Harmony algorithm (HBH) [26] . These algorithm provide search space and optimal one is selected for scheduling to reduce electricity cost and PAR, and user comfort. Dynamic programming are used for the coordination between home appliances. However tradeoff, exist between user comfort and EC. In this article [27], authors designed an architecture for Demand side management and evaluate the performance of home energy management controller using Genetic algorithm GA, binary particle swarm optimization (BPSO), and Ant colony optimization (ACO) algorithm, using time of use (TOU) and inclined block rate (IBR) tariff rate . From result it shows that GA based energy management controller perform well. Authors formulate scheduling problem is a multiple knapsack problem and solve it through ACO. However tradeoff exit between user comfort and EC, when consider user comfort electricity cost will be high or to reduce cost user comfort will be compromise. Researchers proposed an architecture of home Energy management system (EMS) and automated demand response (DR) framework for scheduling smart home appliance [28], using run time price (RTP) and inclined base rate (IBR) a model in which energy price exceed to high level when customer power consumption exceed a threshold, and optimization problem is solve through Genetic algorithm. In this method authors reduce EC and PAR but ignored user comfort. Authors schedule home appliance using bio-inspired GA and BFA [29]. It solve real time scheduling using dynamic programming and using the concept of coordination among home appliances. When large amount of appliances are added then dynamic programming cannot handle. Tradeoff exist between EC and PAR. In this article [30], authors proposed OHEMS which and integrate RES (Renewable Energy Sources ) and ESS (Electricity Storage System), and also implement DSM on it. Different meta-heuristic optimization algorithms are applied like GA, binary particle swarm optimization (BPSO), wind driven optimization (WDO), BFA and proposed hybrid GA-PSO (HGPO) to reduce electricity cost and PAR. However user comfort is not consider. Authors implement DSM (demand side Management) [32], using nature inspired algorithms Elephant herding optimization (EHO), adaptive cuckoo search (ACS) algorithms, and proposed an hybrid algorithm which have both EHO and ACS qualities to reduce EC cost, PAR, and user discomfort. Also used the concept of coordination using Game theory and Dynamic programming. in this article [33], authors designed energy management system for smart home using shuffle frog leaping algorithm (SFLA) for the optimum schedule of different resources like PV (photovoltaic) panels, electric plug-in electric vehicle (PEV), batteries, electric heaters (EH) to balance electric and gas consumption and reduce daily electricity cost. Author in [34], proposed efficient home energy management controller (EHEMC), using heuristic GA, wind driven optimization (WDO), harmony search algorithm (HAS) and proposed a hybrid Genetic harmony search algorithm (GHSA) for single home and multiple home to reduce cost and waiting time of 
appliances, using price tariff RTEP, and CPP. Authors, in [35] proposed HEM scheme to reduce cost, PAR, and user discomfort using heuristic GA, Cuckoo search optimization algorithm (CSOA), and Crow search algorithm (CSA). To improve performance of smart home authors, take electric storage system (ESS). Real time price (RTP), critical peak pricing (CPP) are taken to measure the performance of parameters.

It is observe from literature generally researchers have focus on various conflicting multi-objective problems. Some researchers focus on reducing cost and PAR but user comfort is compromised in in the form of high waiting time. Some of the existing literature focus on reducing cost and PAR along with increasing user comfort. A list of literature review is shown in Table 1.

Table 1. Literature Review

\begin{tabular}{|c|c|c|c|c|}
\hline $\begin{array}{l}\text { Year/ } \\
\text { Reference }\end{array}$ & Name & $\begin{array}{l}\text { Algorithms/ } \\
\text { technique used }\end{array}$ & Key Points & Short Comings \\
\hline $2010[11]$ & $\begin{array}{l}\text { (SHEMS) based } \\
\text { on Zig-Bee } \\
\text { Sensor Network }\end{array}$ & $\begin{array}{l}\text { Disjoint Multi Path } \\
\text { Based Routing } \\
\text { Protocol (DMPR) }\end{array}$ & $\begin{array}{l}\text { Manage Energy at } \\
\text { smart home, real } \\
\text { time information } \\
\text { of energy usage. }\end{array}$ & $\begin{array}{l}\text { There is no such } \\
\text { threshold and } \\
\text { parameters to } \\
\text { control home } \\
\text { appliances. Highly } \\
\text { cost }\end{array}$ \\
\hline $2012[12]$ & $\begin{array}{l}\text { Architecture for } \\
\text { Demand side } \\
\text { load } \\
\text { Management } \\
\text { System (DSM) }\end{array}$ & $\begin{array}{l}\text { Appliance } \\
\text { Scheduling and } \\
\text { Control Algorithm }\end{array}$ & $\begin{array}{l}\text { Integration of } \\
\text { renewable energy } \\
\text { and Load } \\
\text { management at } \\
\text { grid, on the basis } \\
\text { of Real time } \\
\text { Pricing }\end{array}$ & $\begin{array}{l}\text { It will create another } \\
\text { PAR (Peak to } \\
\text { average Ratio) by } \\
\text { shifting load of all } \\
\text { consumer at the } \\
\text { same time. }\end{array}$ \\
\hline $2018[13]$ & SHEMS & $\begin{array}{l}\text { Approximate } \\
\text { Dynamic } \\
\text { programming and } \\
\text { temporal difference } \\
\text { learning }\end{array}$ & Reduce cost, & $\begin{array}{l}\text { User comfort is not } \\
\text { consider }\end{array}$ \\
\hline $2013[25]$ & $\begin{array}{l}\text { Architecture for } \\
\text { Smart Home } \\
\text { Energy } \\
\text { Management } \\
\text { (HEMS) }\end{array}$ & Genetic Algorithm & $\begin{array}{l}\text { Reduce EC and } \\
\text { PAR. }\end{array}$ & $\begin{array}{l}\text { Focus on reducing } \\
\text { PAR (Peak to } \\
\text { Average Ratio) and } \\
\text { EC (Electricity Cost } \\
\text { ) but ignored user } \\
\text { comfort }\end{array}$ \\
\hline
\end{tabular}




\begin{tabular}{|c|c|c|c|c|}
\hline $2014[21]$ & HAEMS & $\begin{array}{l}\text { MO-MINLP } \\
\text { (Multi-object } \\
\text { Mixed integer } \\
\text { nonlinear } \\
\text { programing) }\end{array}$ & $\begin{array}{l}\text { Energy Saving, } \\
\text { reduce EC with } \\
\text { user satisfaction. }\end{array}$ & $\begin{array}{l}\text { Did not consider } \\
\text { PAR }\end{array}$ \\
\hline $2016[22]$ & HEMS & $\begin{array}{l}\text { Functional module } \\
\text { for scheduling }\end{array}$ & $\begin{array}{l}\text { Reduce EC, } \\
\text { Energy efficiently } \\
\text { at power utility }\end{array}$ & $\begin{array}{l}\text { Model is not suitable } \\
\text { for Cold region, no } \\
\text { coordination among } \\
\text { renewable and } \\
\text { sustainable energy }\end{array}$ \\
\hline $2017[27]$ & OHEMS & $\begin{array}{l}\text { GA, WDO, BFO, } \\
\text { Hybrid GA-PSO } \\
\text { (HGPO) }\end{array}$ & $\begin{array}{l}\text { Reduce EC and } \\
\text { PAR }\end{array}$ & $\begin{array}{l}\text { Coordination among } \\
\text { renewable and } \\
\text { sustainable energy } \\
\text { is not addressed }\end{array}$ \\
\hline $2018[16]$ & $\begin{array}{l}\text { MPC (A Model } \\
\text { Prediction } \\
\text { Controller) }\end{array}$ & $\begin{array}{l}\text { MIQP (Mixed } \\
\text { Integer Quadratic } \\
\text { Programming ) }\end{array}$ & $\begin{array}{l}\text { Reduce EC, User } \\
\text { Comfort specially } \\
\text { Thermal comfort }\end{array}$ & PAR is not consider \\
\hline $2018[29]$ & $\begin{array}{l}\text { DSM (Demand } \\
\text { side } \\
\text { management) }\end{array}$ & $\begin{array}{l}\text { EHO, ACS, HEAC } \\
\text { coordinating with } \\
\text { Game theory (GA) } \\
\text { and Dynamic } \\
\text { programming (DP) }\end{array}$ & $\begin{array}{l}\text { Reduce EC, reduce } \\
\text { PAR, Maximize } \\
\text { User Comfort }\end{array}$ & $\begin{array}{l}\text { Tradeoff exist } \\
\text { cannot achieve best } \\
\text { values for EC, PAR, } \\
\text { and user comfort at } \\
\text { the same time }\end{array}$ \\
\hline $2018[23]$ & HEMS & BFA,HSA, HBH & $\begin{array}{l}\text { Reduce EC, PAR } \\
\text { and increase User } \\
\text { comfort }\end{array}$ & $\begin{array}{l}\text { Tradeoff exist } \\
\text { between electricity } \\
\text { Cost and User } \\
\text { Comfort, no } \\
\text { solution for Big } \\
\text { Data created by } \\
\text { multiple homes }\end{array}$ \\
\hline $2018[26]$ & HEMS & $\begin{array}{l}\text { HBG, GA, BFA } \\
\text { using Dynamic } \\
\text { programming }\end{array}$ & $\begin{array}{l}\text { Reduce EC, PAR, } \\
\text { and maximize user } \\
\text { comfort }\end{array}$ & $\begin{array}{l}\text { Tradeoff exist } \\
\text { between EC and } \\
\text { user comfort }\end{array}$ \\
\hline
\end{tabular}

\section{PROBLEM STATEMENT}

Irregular usage of electricity increase load on utility, thus extra an generation of electricity require at some specific hours to overcome electricity demand, this will increase PAR and electricity cost at peak hours. To educate consumers to optimally use electricity DSM is used for optimal use of energy we need an efficient algorithm for HEMS to shift load from On-peak hours to Off-peak hours in a balance 
way. Researchers have used many system is to minimize cost, PAR, and increase user comfort, but trade-off always exist between cost and PAR and cost and comfort, thus researchers did not consider all the targets at the same time. Researchers in [15] [16], [21], did not consider PAR which will create a burden on utility. While, [21], [25], did focus on reducing PAR but ignore EC and user comfort.

If sudden change in electricity usage occur this is an issue, author in [29], reschedule home appliances on the basis power in which high priority appliances are $\mathrm{ON}$ according to the user requirement at real time and the running appliance is schedule to next scheduled appliance during the next hour, but it increase on end hour because of static input. Thus the concept of coordination is used for dynamic scheduling [30] designed a system provide consumer to reschedule appliance at real time with coordination with energy management unit. Thus rescheduling operation need flexible system neither it create peak nor effect cost and comfort.

\section{PROPOPSED SYSTEM MODEL}

To efficiently utilize energy HEMS is designed in this section. We assume a smart home have smart appliances which communicate with the energy management system. Monitoring unit which communicate with utility for price signal, it monitor user power demand. Management unit which schedule home appliance and control unit which decide to which appliance should be ON or OFF according to assign working hour. HEMS work efficiently depend upon fair coordination between user and system. Run time scheduling is the responsibility of management unit, in which one appliance is turn OFF and other appliance is reschedule is particular space time.

The overview of system model is proposed in Fig. 1. It demonstrated that power flow and service is flow between service provider and end user. Smart meter deployed in each smart home have two way communication system, communicate between consumer and utility by sending power consumption of user to grid and grid response to sending electric signal price. The proposed optimization technique for HEMS schedule smart home load on day-ahead and real time basis using met-heuristic algorithm. The main objective is of our proposed model is to reduce electricity cost and PAR. And for user comfort real time scheduling is used, real time scheduling is a Knapsack problem and solved through ACO algorithm. 


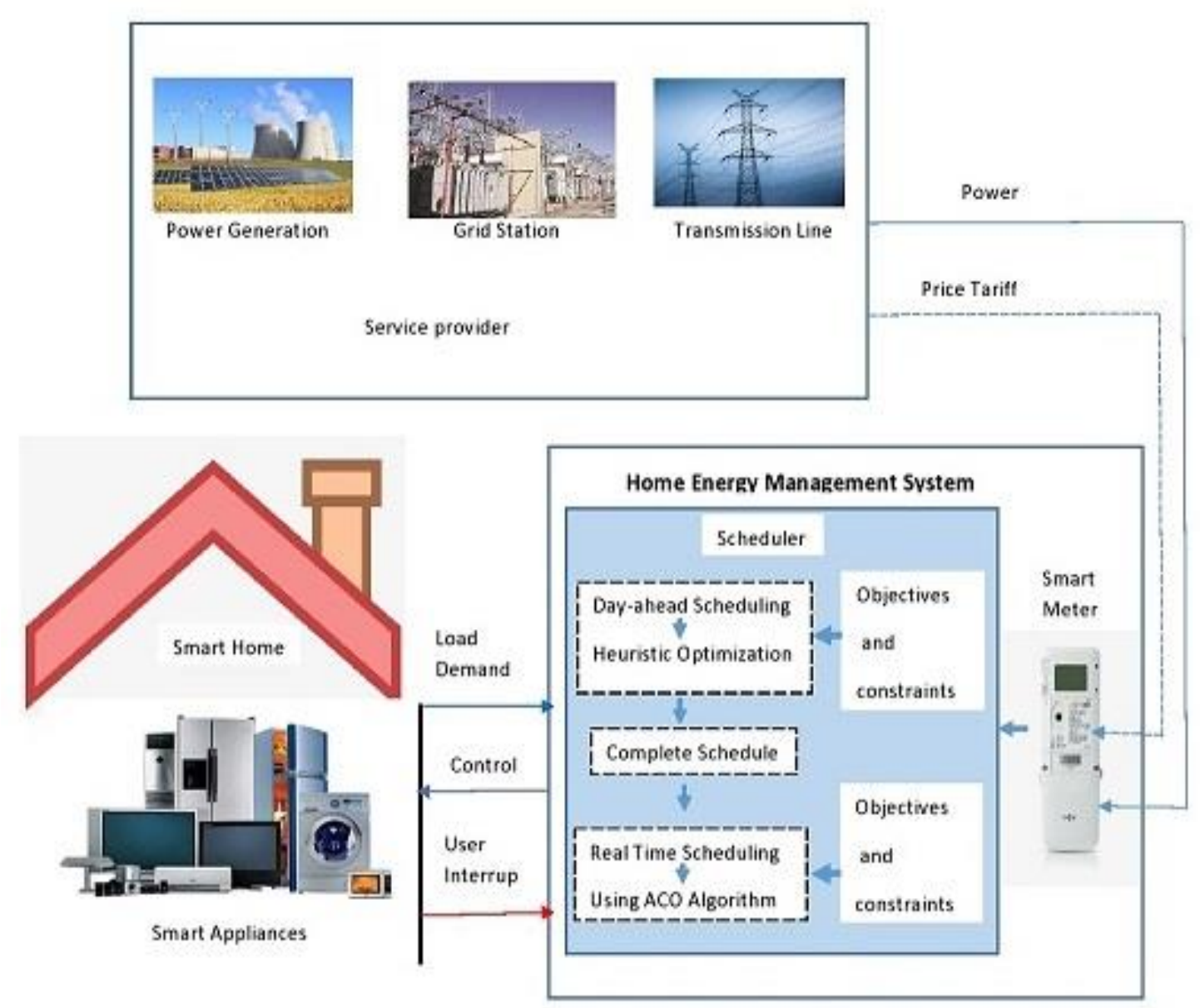

Fig. 1 System Model and information flow between service provider and user

\section{A. Problem formulation}

The proposed HEMS shifts the load on a day-ahead basis. Considering the scheduling techniques, we focus on achieving multiple objectives. The day-ahead objective includes the minimization of the electricity cost, PAR and minimizing the distance between the objective load curve and the actual energy consumption pattern. The day-ahead model for home load management is given by the following:

\section{1) Load Shifting:}

To schedule home appliances in a balance way neither it create PAR nor it compromise user comfort the proposed algorithms schedule home appliance optimally. Power consumption of appliances during a particular hour is given in equation 1 .

$\mathrm{K}_{l}$ electric power load per hour, represent average load of $\mathrm{ON}$ appliance during a particular time. 


$$
\mathrm{K}_{l}=\sum_{\mathrm{a}=1}^{D} \mathrm{APP}_{p_{\text {rate } * \rho}^{\mathrm{a}}}^{\mathrm{a}}
$$

$\rho=1,0$ represent $\mathrm{ON}$ and OFF status of appliance during a particular hour and $\mathbf{D}$ represent number of appliances.

\section{(2) Electricity Cost Minimization:}

Second objective is cost minimization which can be mathematically represented as follow:

$$
M_{1}=\min \left(\kappa_{\text {cost }}^{\text {total }}\right)
$$

$\mathrm{K}_{\text {cost }}^{\text {total }}$ total electricity cost of all appliances for a single day.

where per hour cost is calculated using equation 3 .

$$
\mathrm{K}_{\text {cost }}^{\text {hour }}=\sum_{a=1}^{D}\left(E_{\text {price }}^{\text {hour }} * \mathrm{App}_{p_{\text {rate }}}^{d} * \rho\right)
$$

$\mathrm{APP}_{p_{\text {rate }}}^{d}$ represent power consumption of each appliance is given in table 2.

\section{(3) PAR reduction:}

To maintain grid stable it is necessary to reduce PAR. The reduction of PAR is one the objective of research, it can be mathematically represented as:

$$
M_{2}=\min (P A R)
$$

which is accomplished by equation 1. Formally, the PAR can be written as:

$$
P A R=\frac{\max \left(\mathrm{K}_{\text {load }}^{N}\right) 2}{\left(\operatorname{avg}\left(\mathrm{K}_{\text {load }}^{N}\right)^{2}\right.}
$$

where $\kappa_{\text {load }}^{N}$ is equal to $\left\{\mathrm{K}_{\text {load }}^{1}, \mathrm{~K}_{\text {load }}^{2}, \ldots . ., \mathrm{K}_{\text {load }}^{24}\right\}$ is a per hour electricity load calculated using equation 1 .

\section{(4) User Comfort}


In some situation user want to turn off an appliance and reschedule other appliance in this particular time to reduce waiting time of that appliance. This will maximize user comfort, which can be written mathematically as follows:

$$
M_{3}=\max (\text { Comfort })
$$

When interrupt ${ }^{\mathbf{T}}$ occur to switch Off appliance and request for real time scheduling from list of reschedule appliances $A \mathrm{AP}_{\text {list }}^{\Gamma}$. Mathematically represented as follows:

$$
\mathrm{APP}^{\Gamma}=\left\{\begin{array}{cc}
1 & \text { if } \\
0, & \text { otherwise }
\end{array}\right.
$$

$\mathrm{APP}_{\text {wait }}^{d} \quad$ Appliance waiting time and comfort have inverse relation with each other.

Waiting time of appliance $\mathrm{d}$ is calculated equation 8 .

$$
\mathrm{APP}_{\text {wait }}^{d}=\min \left|\mathrm{AP} \mathrm{P}_{\text {demandh }}^{d}-\mathrm{APP}_{\text {scheduleh }}^{d}\right|
$$

\section{B. Proposed algorithm}

In this research we follow the concept of hybridization to solve scheduling problem of smart building. We proposed a model called hybrid Bacterial foraging and Ant Colony optimization algorithm (HB-ACO). The purpose of our proposed model is load shifting to reduce cost and electricity, moreover we are using concept of coordination among appliances and consider as knapsack problem and solve it through ACO algorithm. The proposed model have two algorithms discuss below:

(1) Day-ahead Scheduling:

In this research we follow the concept of hybridization to solve scheduling problem of smart building. We proposed a model called hybrid Bacterial foraging and Ant Colony optimization algorithm (HB-ACO). Bacterial foraging optimization algorithm have three 
steep chemotatic, reproduction and elimination and dispersal. Chemotatic is the life time of bacteria by taking different steps for searching food, reproduction is when specific group of bacteria have good performance in their life cycle are selected for next generation, in elimination and dispersal bacteria are discarded due to poor performance and new random samples are introduce with low probability. Following these step at the end best solution is used for schedule.

To improve efficiency of BFA we are using ACO algorithm together with BFA. BFA select best population from a group of bacteria having low cost during their searching for food and eliminate bacteria having less nutrient or not favorable environment and dispersed other bacteria with less probability with elimination and dispersal. We use pheromone trial of ACO algorithm and select a population through probability having high pheromone level and with less pheromone level are eliminate to select a best population. The proposed hybrid algorithm can replace elimination and dispersal step of BFA through update pheromone and probability selection of ACO. 


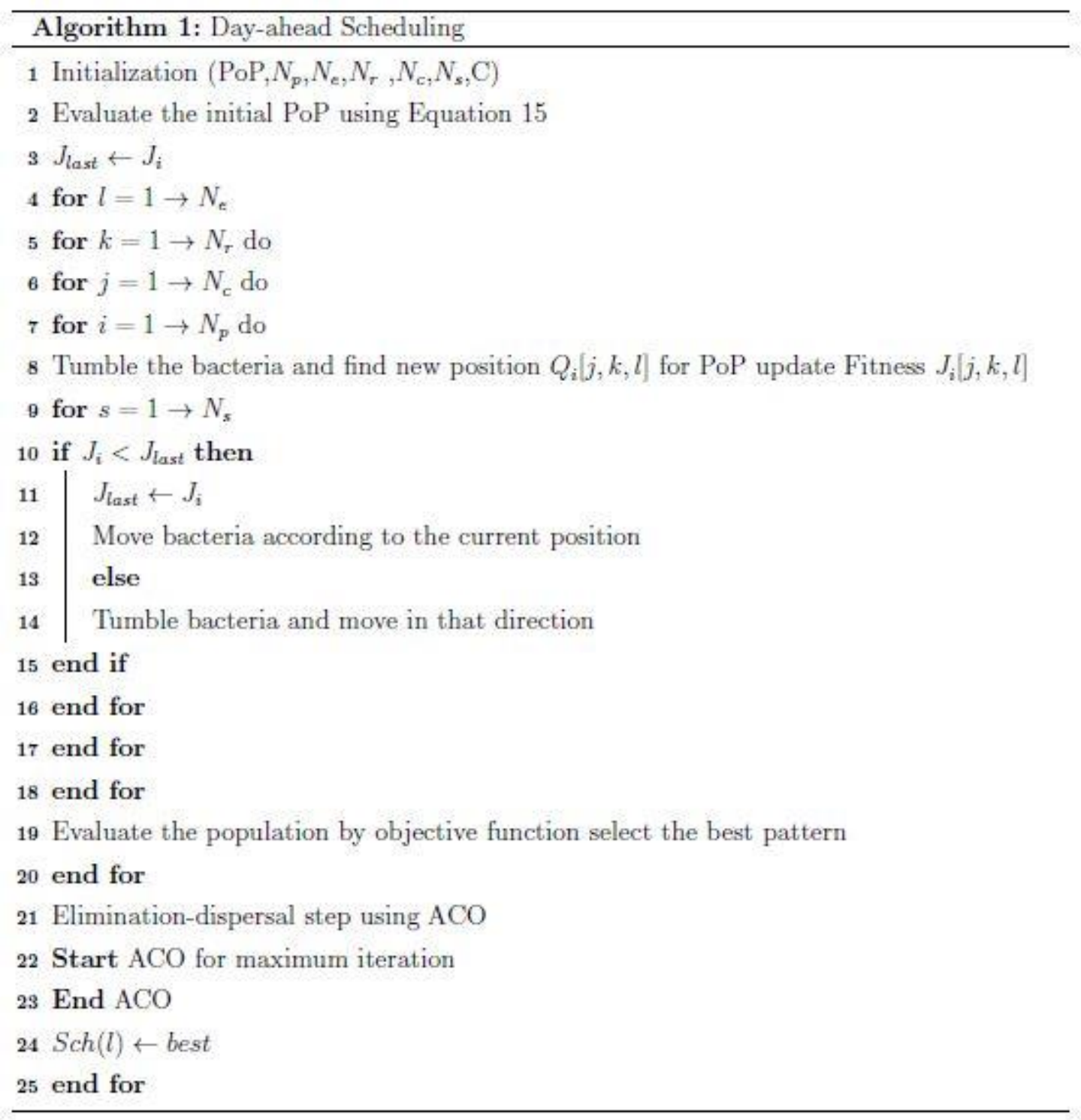

\section{a) ACO:}

Ant search for food at random direction and deposit some chemical called pheromone. Depending on pheromone level and attractiveness function other ant follow route having maximum pheromone because ant have sensing ability. After some time all ants follow the shortest route. Marco Dorigo, [33] present this concept in computer programming to solve complex problem.

The amount of pheromone level deposit by an ant is mathematically represented as follow:

$$
\Delta \tau_{i, j}^{k}=\left\{\begin{array}{l}
\frac{1}{L_{k}} \text { if } k_{t h} \text { ant travel from edge } i \text { to } g \\
0, \text { otherwise }
\end{array}\right.
$$


where $\Delta_{\tau}$ represent amount of pheromone deposit by ant k travelling from edge i to j. In $\frac{1}{L_{k}} L_{k}$ represent length of path found by kth ant, the shorter the path the higher pheromone should be deposit by the ant.

pheromone level with out vaporization:

$$
\tau_{i, j}^{k}=\sum_{k=1}^{m} \Delta \tau_{i, j}^{k}
$$

Pheromone level with vaporization:

$$
\tau_{i, j}^{k}=(1-\rho) \tau_{i, j}+\sum_{k=1}^{m} \Delta \tau_{i, j}^{k}
$$

if $\rho$ is equal to 1 it mean all pheromone are evaporate before depositing new pheromone. If $\rho$ is equal to 0 it mean no vaporization.

The probability of ant to select a node is mathematically represented as follow:

$$
P_{i, j}=\frac{\left(\tau_{i, j}\right)^{\alpha}\left(\eta_{i, j}\right)^{\beta}}{\sum\left(\left(\tau_{i, j}\right)\left(\eta_{i, j}\right)\right)}
$$

$P_{i, j}$ represent the probability of choosing edge $\mathrm{i}$ and $\mathrm{j}$. Where $\eta_{i, j}$ represent quality of edge $i$ and $j$ on the graph. We are interested in shortest path so,

Where

$$
\eta_{i, j}=\frac{1}{L_{i, j}}
$$

$\alpha$ and $\beta$ are used to find relative importance between pheromone and distance.

\section{b) BFA:}

To represent the social behavior bacterial foraging in a computer program M. Passino, represent an algorithm to solve complex engineering problem [34]. Bacterial foraging optimization is a nature inspired technique to find the optimal solution of a problem When E. Coli bacteria search for food it follow three steps: Chemotaxas, Single bacterium or a group of bacteria swim for food, when it find environment with good nutrients it swim further to gain more nutrients to perform extra activates like reproduction, sleep. Otherwise it will tumble mean change its position.

To represent cell-to-cell attractant effect to the nutrient as follow.

$$
J[j, i, k]=J[j, k, l]+J_{c c} \theta^{i}(j, k, l), P(j, k, l)
$$


Where $J_{c c}$ is calculated using Rosenbrock equation given below:

$$
J_{c c}=\sum_{d=1}^{M}\left(100 \times\left(\theta(i, d+1)-(\theta(i, d)-1)^{2}\right)^{2}+(\theta(i, d)-1)^{2}\right)
$$

When a bacteria change its position this is represented as follow:

$$
\theta^{i}[j, k, l]=\theta^{i}(j, k, l)+C(i) \frac{\Delta(i)}{\sqrt{\Delta^{\rho} \Delta(i)}}
$$

Where $\Delta$ is a vector having value between [-1 to 1$]$

reproduction: When a group of bacteria swim for food and perform well in their life time gain more food having less cost function. These bacteria will reproduce next generation in a constant way. Reproduction of $i_{t h}$ bacteria having $k_{t h}$ chemotactic step and $l_{t h}$ reproduction step is represented as follow:

$$
J_{\text {health }}^{i}=\sum_{j=1}^{N_{c}+1} J(i, j, k, l)
$$

$\mathrm{n}$ and dispersal: Due to unfavorable condition like less nutrients, high temperature. These bacteria are killed are eliminate to some other place and dispersed other bacteria having low probability. Elimination and dispersal destroy chemotaxis progress, but the other hand dispersal may put bacteria in a place having good nutrients.

\section{(c) HB-ACO}

In this research we follow the concept of hybridization to solve scheduling problem of smart building. We proposed a algorithm called hybrid Bacterial foraging and Ant Colony optimization algorithm (HB-ACO) explained in algorithm 1. HB-ACO followed the step of BFA as explained in previous section with the difference elimination and dispersal. The proposed algorithm replace elimination and dispersal step of BFA which randomly eliminate bacteria after reproduction survive for next generation, through update pheromone and probability selection. 


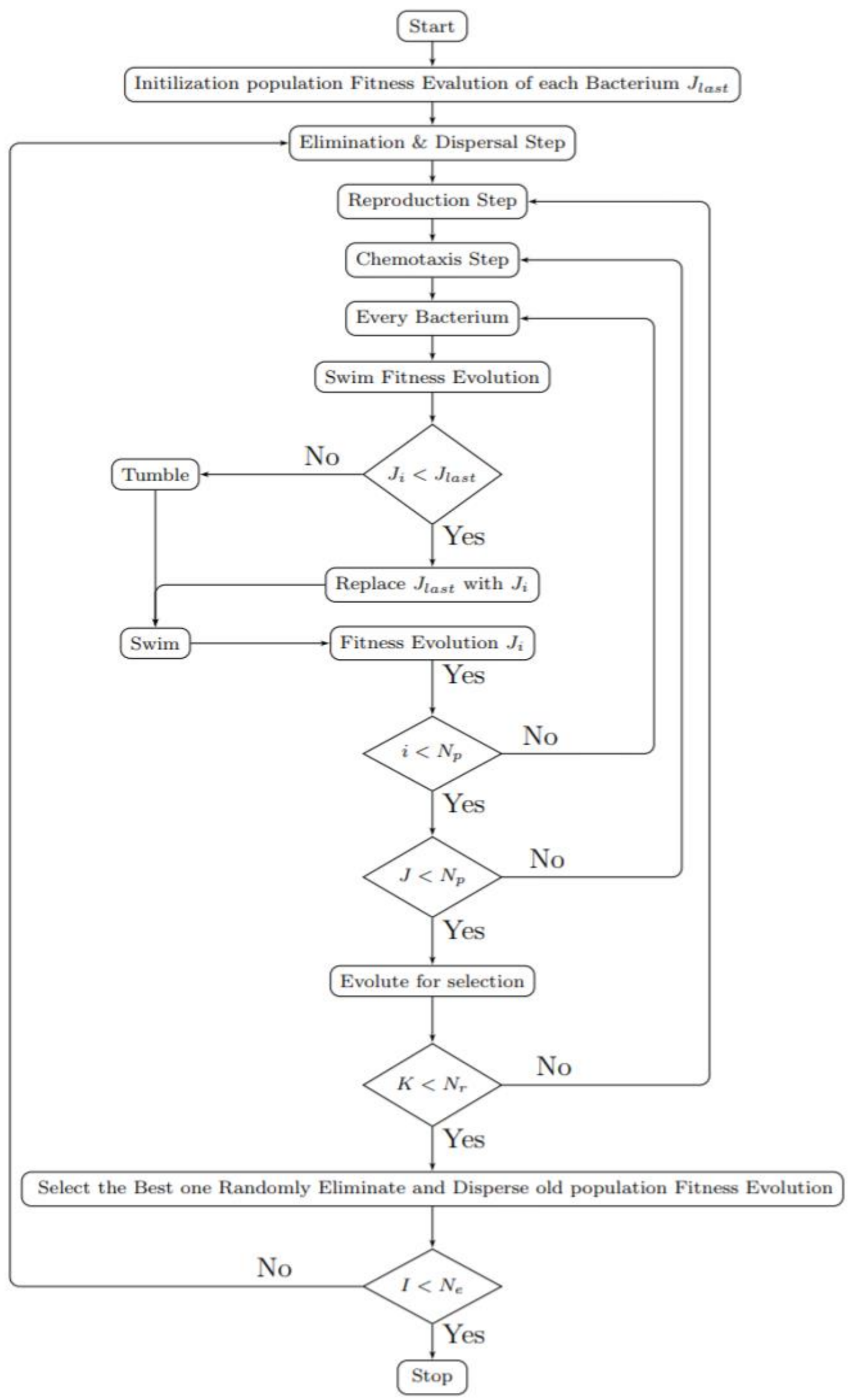

Fig. 2 Flow Chart of BFA 


\section{Real time Scheduling:}

When a user interrupt in emergency situation to use high priority appliance the scheduler switch off such appliance at real time and allocate the reaming time of appliance to high priority appliance. We consider this problem is a knapsack problem and to solve this problem we are using Ant Colony Optimization algorithm. For selection we generate artificial ant which calculate width of object which is operational time of particular appliance and cost of object which is total cost of object in that particular hour. We consider Knapsack capacity is the reaming time of stooped object.

Start real time scheduling by scheduling 24 hours in to On-peak and Off-peak discuss in Table 3 and Table 4.

Also schedule home appliance according to load scheduled those appliance which use less electricity during On-peak hours and schedule appliance with high load in Off-peak hours in a balance way. if Interrupt occur during emergency we consider this is Knapsack problem. Stop appliance and calculate reaming time of running appliance and allocate this time to Knapsack Capacity.

ACO start its working by moving an artificial ant containing a list of appliances $\mathrm{APP}_{\text {list }}^{\Gamma}$ to reschedule. Where knapsack Capacity is available time interval when an interrupt ${ }^{\mathbf{T}}$ occur. Weight of an item is consider is operations time of a particular appliance and value is cost of appliance during particular hour depend upon operational time and price signal.

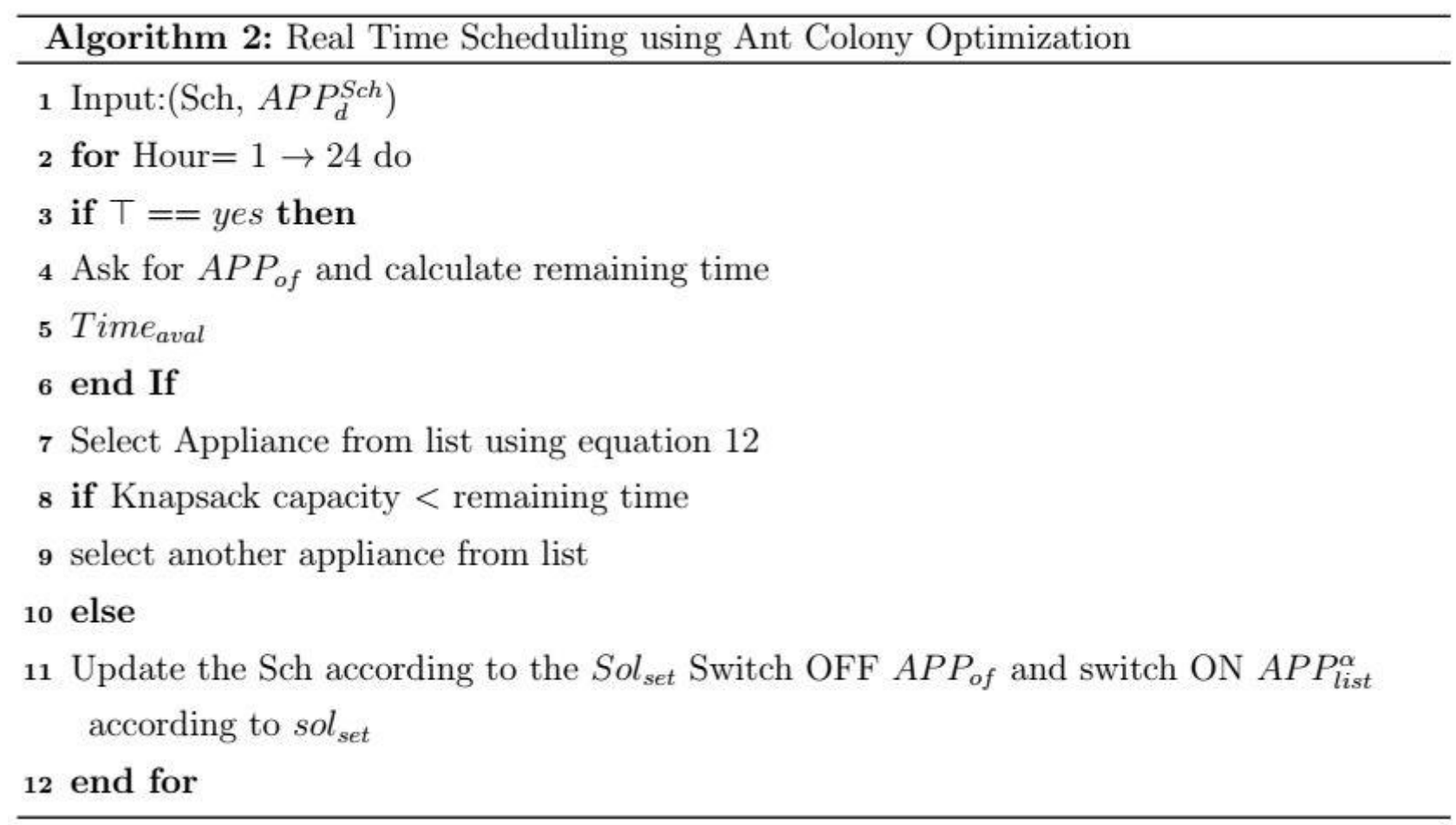




\section{Section V. Result and Discussion}

Home appliances are divided into three categories on the basis of power consumption. Interruptible burst load are such appliances which can be turn OFF or ON any time during a day. For example water heater, vacuumed cleaner, water pump, water heater. Non-interruptible appliance which cannot disturb during their execution time. Example of non-intractable load are washing machine, cloth dryer. Base load is the regular load of home which cannot be change or shift during their execution time. Example are refrigerator, lighting, computer, oven, AC. Maximum and minimum power consumption of appliances are taken from [35]

Table 2. Power rate and consumption

\begin{tabular}{|l|l|l|l|}
\hline Category & Appliances & Power Rating (KWh) & Daily usage (hours) \\
\hline Interruptible load & Water heater & 4.8 & 10 \\
\cline { 2 - 4 } & Water Pump & 0.7 & 4 \\
\cline { 2 - 4 } & Dish washer & 1.7 & $<4$ \\
\cline { 2 - 4 } & Iron & 1.2 & 2 \\
\hline Base Load & Refrigerator & 0.3 & 20 \\
\cline { 2 - 4 } & AC & 4.5 & 12 \\
\cline { 2 - 4 } & TV & 0.25 & 2 \\
\cline { 2 - 4 } & Oven & 1.6 & 4 \\
\hline Non-interruptible load & Washing Machine & 0.45 & 3 \\
\cline { 2 - 4 } & Cloth dryer & 3.8 & 2 \\
\hline
\end{tabular}

\section{Price Tariff:}

Time of Use ToU

This is time base pricing scheme where day are divided into different block and price are fixed for different blocks [36]. The load is dived into peak hour, mid peak hours and On- peak hour. Price in On-peak hours are high then other pricing scheme. 
Table 3. Summer ToU time

\begin{tabular}{|l|l|l|}
\hline S. No & Time & ToU \\
\hline 1 & 11:00 AM to 4:00 PM & On-peak hours \\
\hline 2 & 7:00 AM to 10:00 AM & MID-peak hours \\
\hline 3 & 1:00 AM to 6:00 PM & Off-peak hours \\
\hline 4 & 5:00 PM to 6:00 PM & MID-peak hours \\
\hline 5 & 7:00 PM to 12:00 PM & Off-peak hours \\
\hline
\end{tabular}

Critical Peak Pricing CPP

During summer weekday a critical event may occur when utility observe high market price. Electricity price are high during this critical event. Utility define two variants for CPP first price of peak hour are predefined and second electricity rate depend on demand to reduce load on grid. Theses hours are limited 10 to 15 times during a season. From [37] CPP are taken.

Table 4. Summer CPP time

\begin{tabular}{|l|l|l|}
\hline S. No & Time & CPP \\
\hline 1 & 11:00 AM to 4:00 PM & On-peak hours \\
\hline 2 & 5:00 PM to 12:00 PM & Off-peak hours \\
\hline 3 & 1:00 AM to 10:00AM & On-peak hours \\
\hline
\end{tabular}

\section{Result before coordination:}

In this section proposed solution are analyzed using two different pricing rates: ToU and CPP. Fig. 5 and Fig. 8 show that price for unscheduled load is high for both tariffs. Fig. 5 and fig. 8 show the total unscheduled electricity cost 1800 cents for ToU and 6700 cents for a CPP. The simulation results before coordination are clear from Figs. 3, fig. 4 and 5. From result it is clear that implemented optimization techniques shift load which directly affect electricity cost shows if figure 3. HB-ACO shows relatively low price signals for high peak hours. Graphical representation of per hour cost for an unscheduled and HB-ACO proposed approach along with ACO and BFA are shown in Fig. 5. Due to load shifting from On-peak hours to Off-peak hours cost payed is less compare to unscheduled load. 
Performance of HB-ACO for ToU tariff compare with other two approaches is better, HB-ACO has reduced $48 \%$ PAR and $17 \%$ cost. Cost reduction of BFA is same as HB-ACO but PAR is comparatively higher than HB-ACO. For the CPP, HB-ACO again outperformed and reduced $42 \%$ PAR and $40 \%$ cost. Though, PAR reduction of ACO is $57 \%$. From simulation it shows that HB-ACO outperform other two approaches on the basis of cost reduction and high PAR with less waiting time as well as low convergence rate.

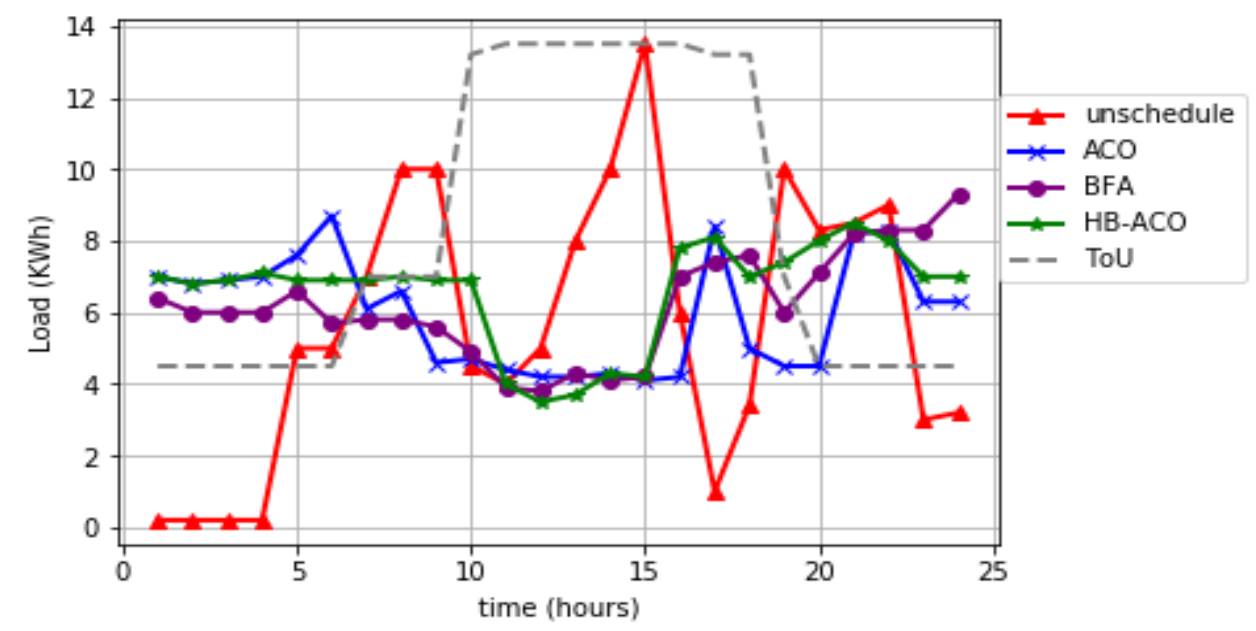

(a) $\mathrm{ToU}$

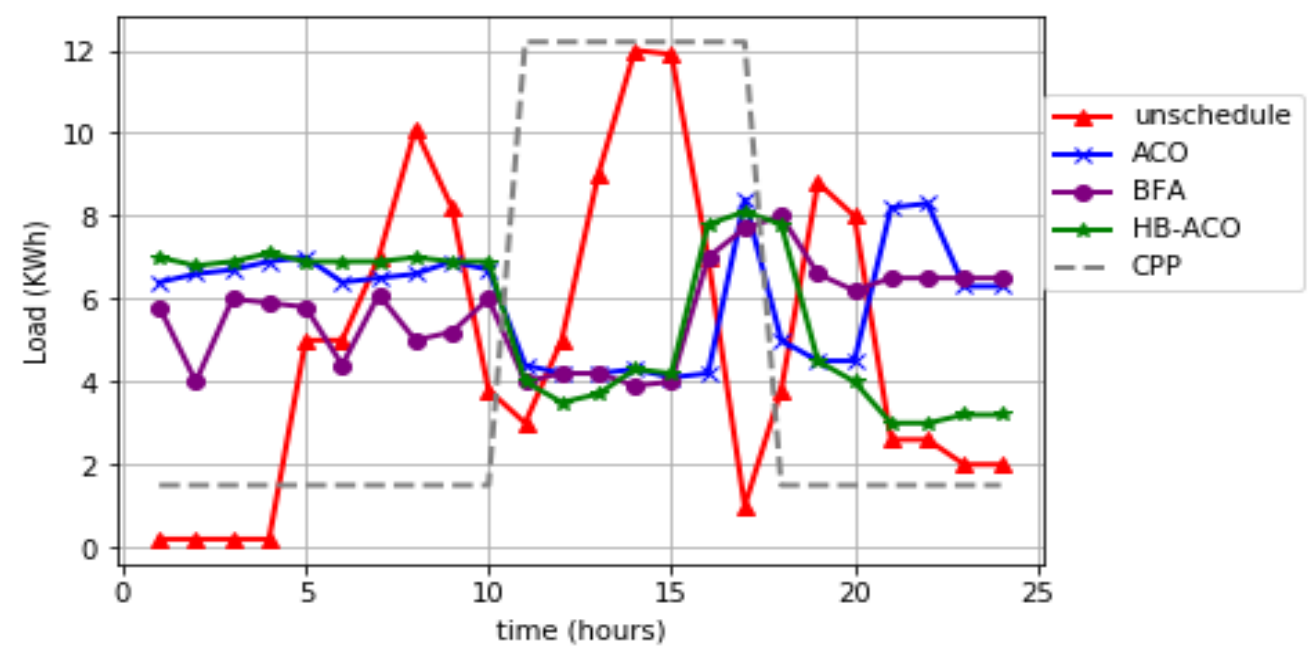

(b) CPP

Fig. 3. Per hour scheduled load before coordination. 


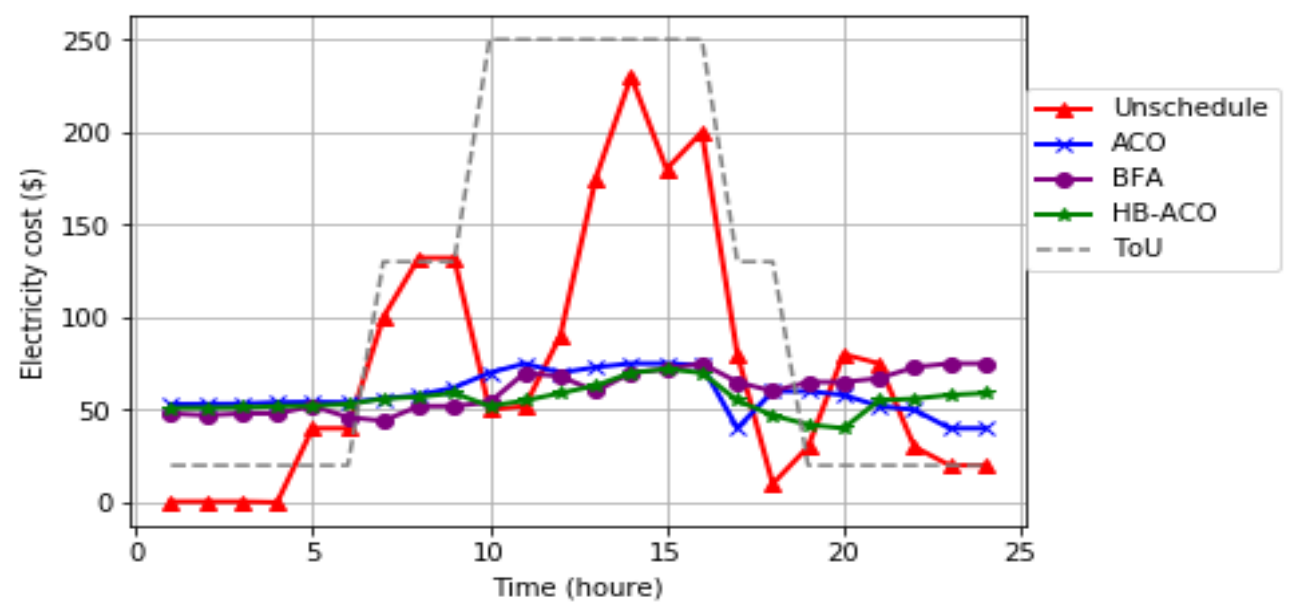

(a) ToU

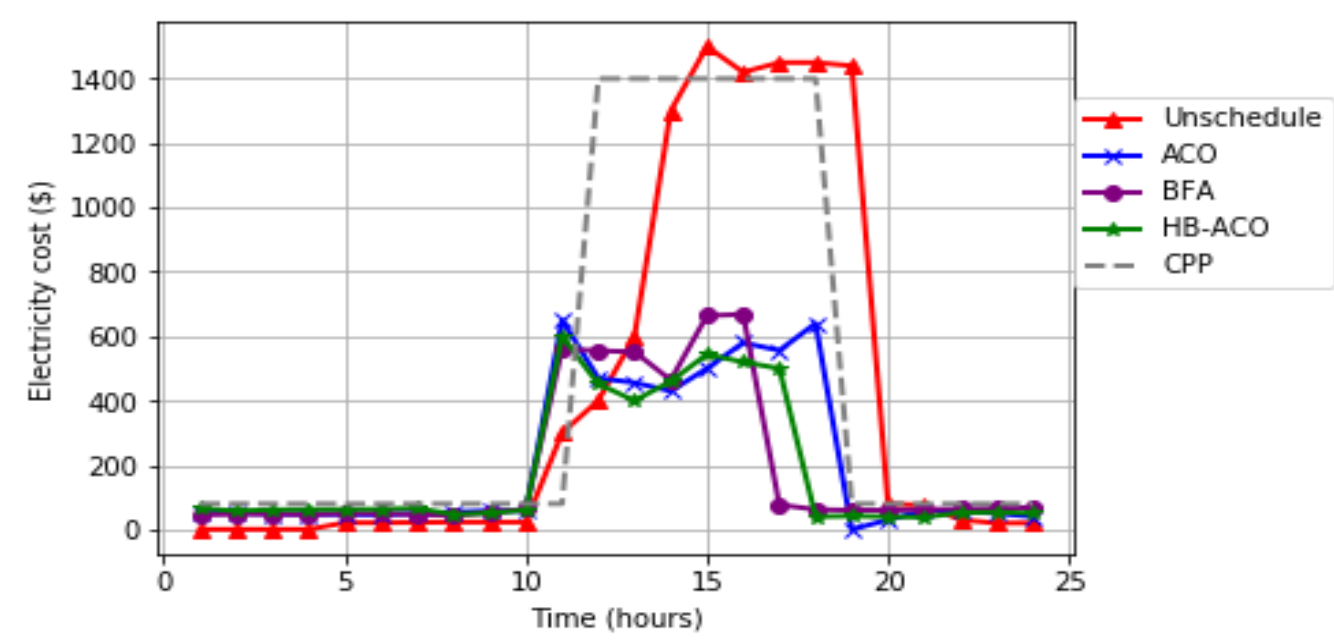

(b) CPP

Fig. 4. Electricity cost before coordination for (a) TOU. (b) CPP.

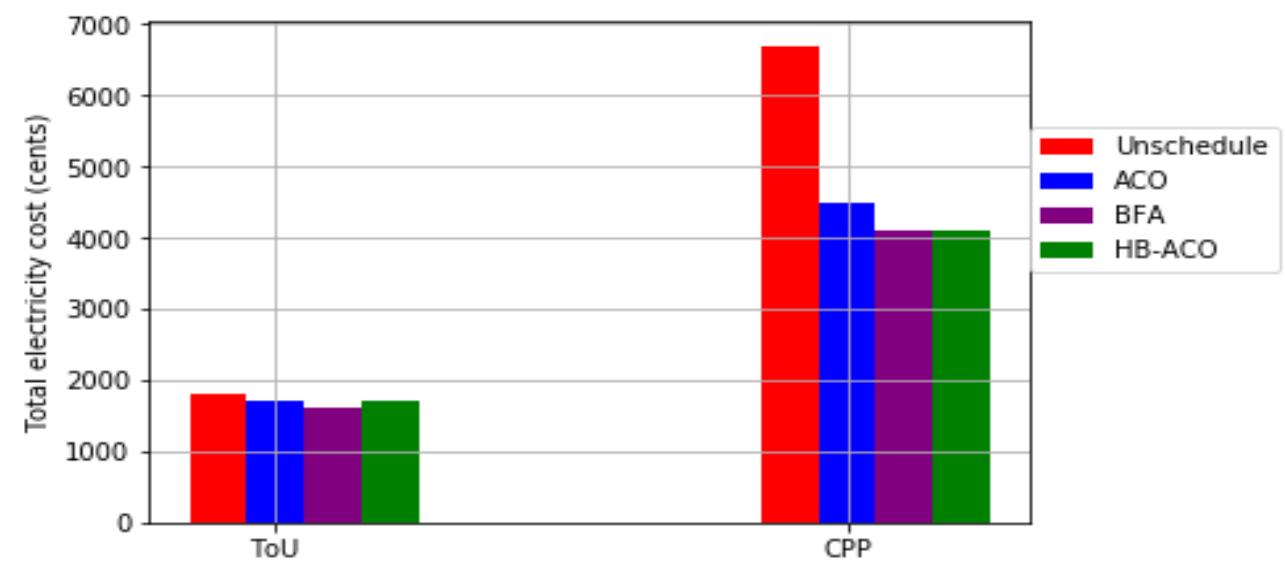

Fig. 5 total electricity before coordination for a day. 


\section{Result After coordination}

Heuristic algorithms perform well as compare to evolutionary approaches, where hybrid algorithms outperform both algorithm use in this paper as shown if figure 8. It also shown from fig. 8 that $5 \%$, $8 \%$ and $8 \%$ less cost than without coordination, for ACO, BFA and HB-ACO. Fig. 8 clearly shown $5 \%$ maximum cost is reduced by $\mathrm{HB}-\mathrm{ACO}$ with $9 \%$ increase in PAR and $14 \%$ reduce waiting time shown in fig. 12. However, tradeoff occur between PAR and cost during coordination because sometimes it passes heavy load appliance. From result it clearly shows the difference between before and after coordination because of reduction in the load and increase in the peak load.

Simulation result further shows that there is tradeoff between cost, PAR and waiting time of appliances Table 5 shows affect on electricity cost , PAR and waiting time after coordination. Difference between before and after waiting time for base load and interruptible load appliances because list of reschedule appliance belong to this category. 


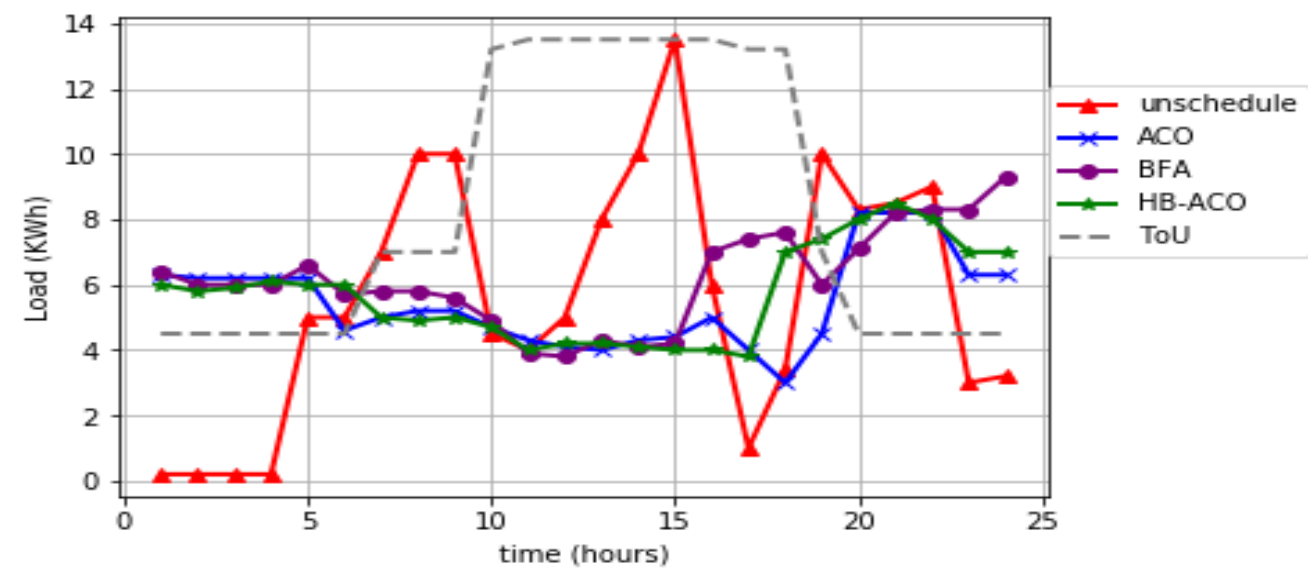

(a) TOU

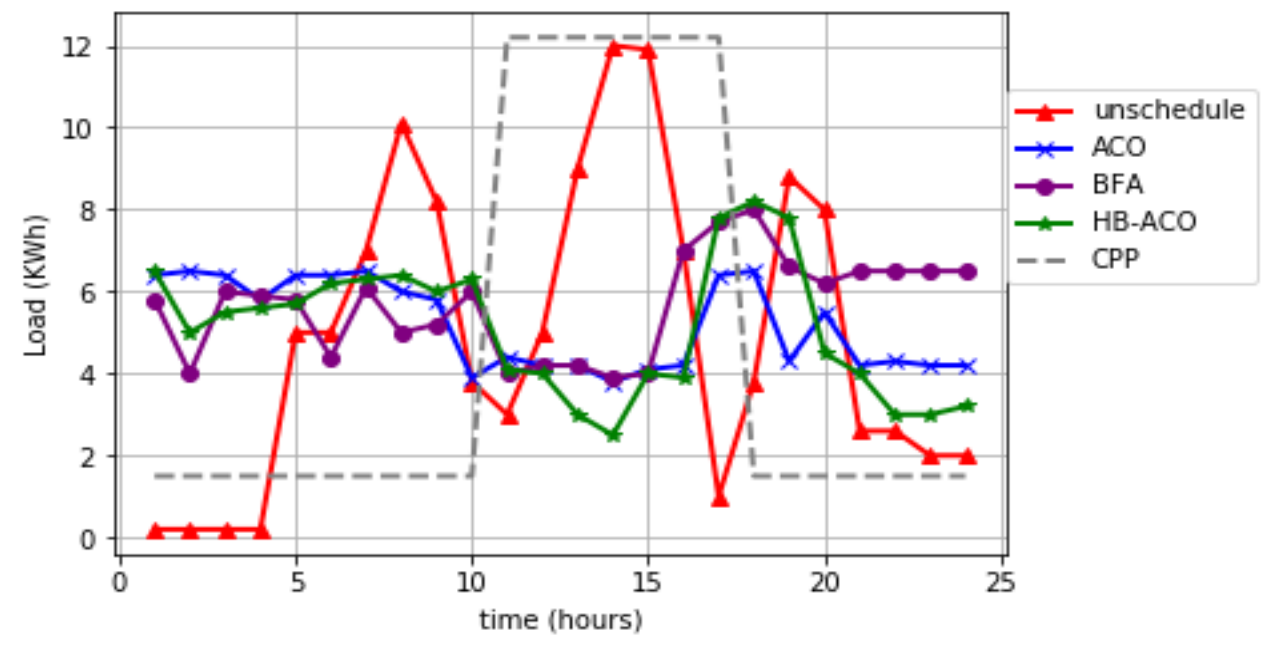

(b) CPP

Fig. 6 Per hour scheduled load after coordination.

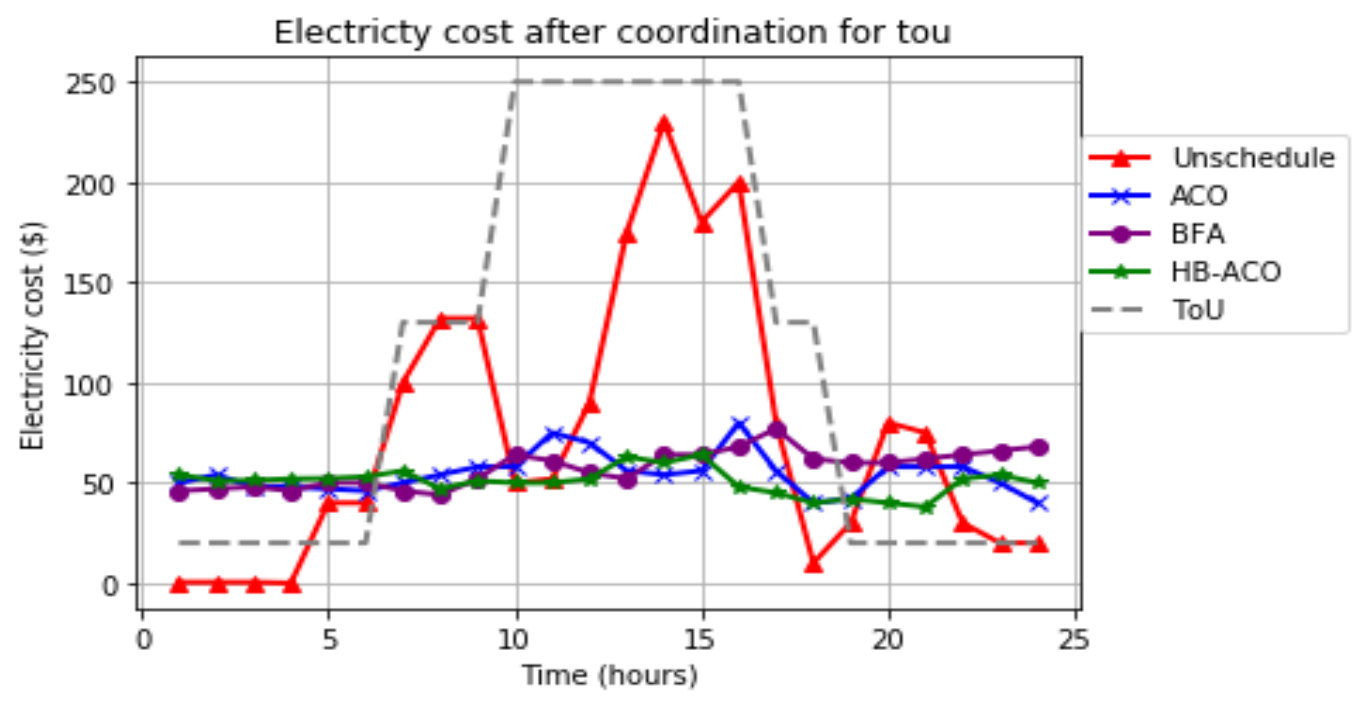

(a) ToU 


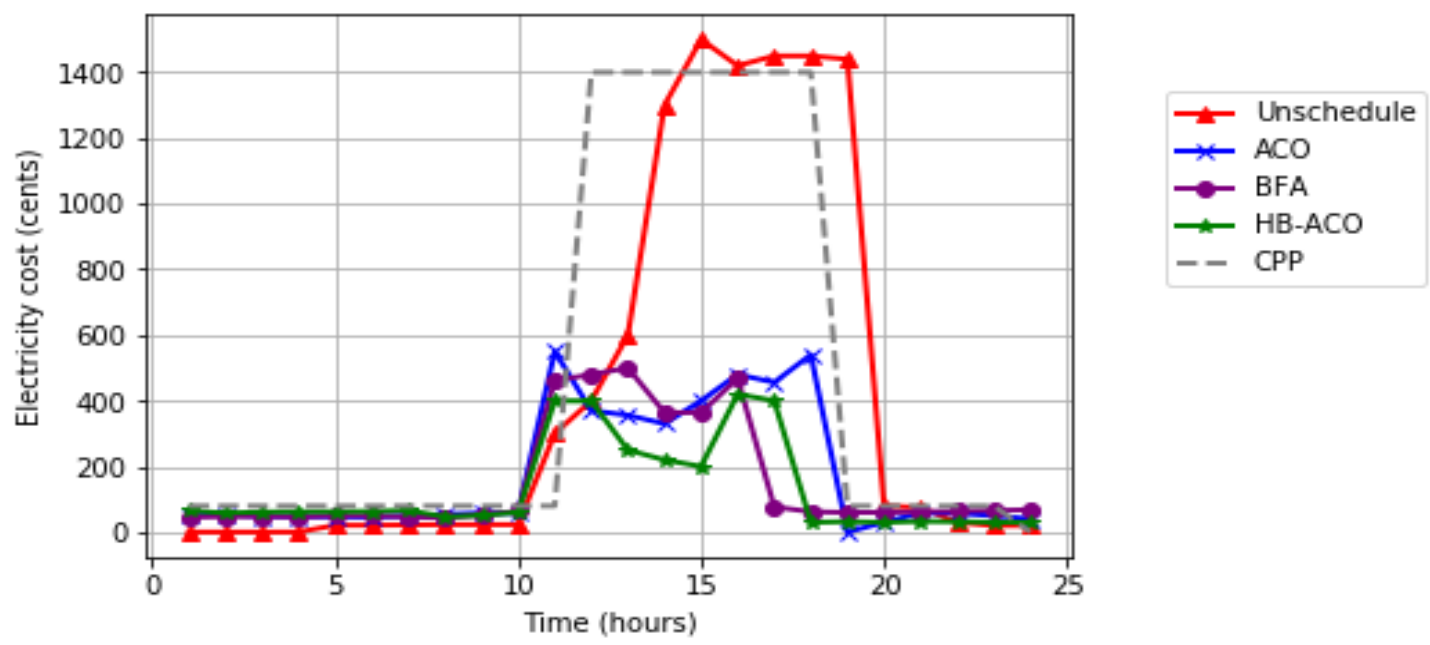

(a) CPP

Fig. 7. Electricity cost of each hour during a day after coordination (a) TOU. (b) CPP

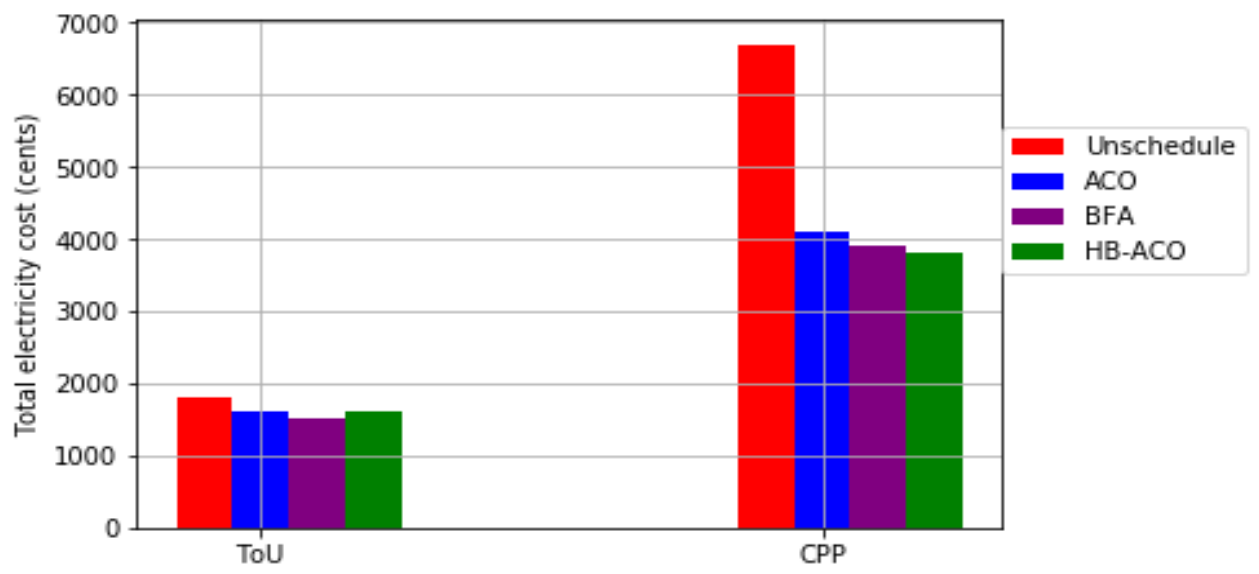

Fig. 8. Impact of coordination on total electricity for a day. 


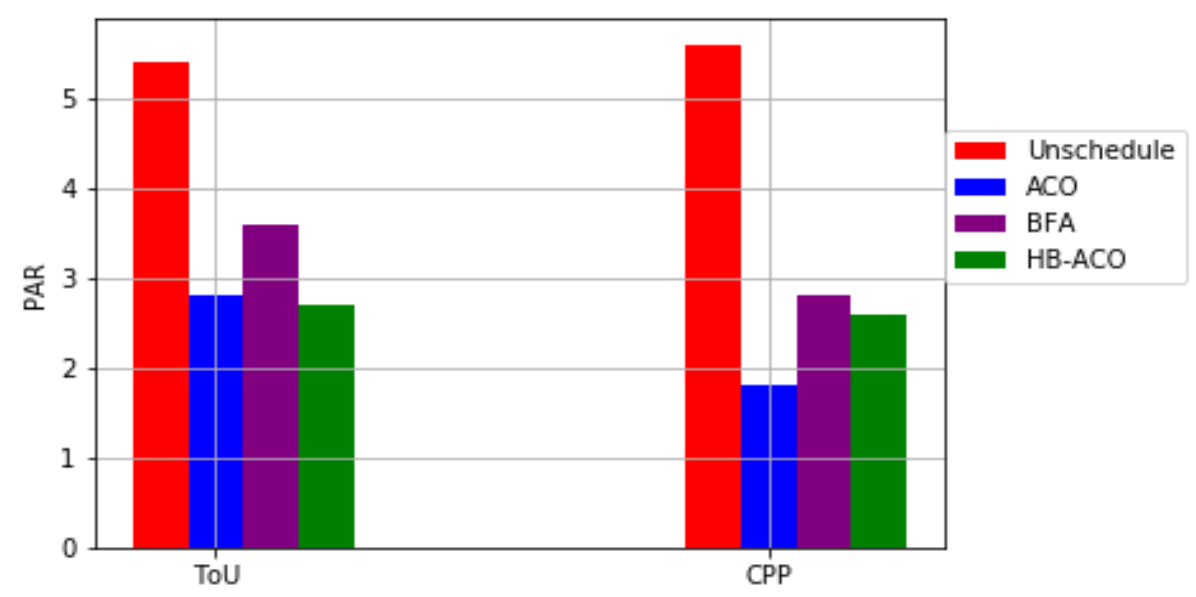

Fig. 9. PAR for proposed HB-ACO and adopted ACO and BFA approaches without coordination

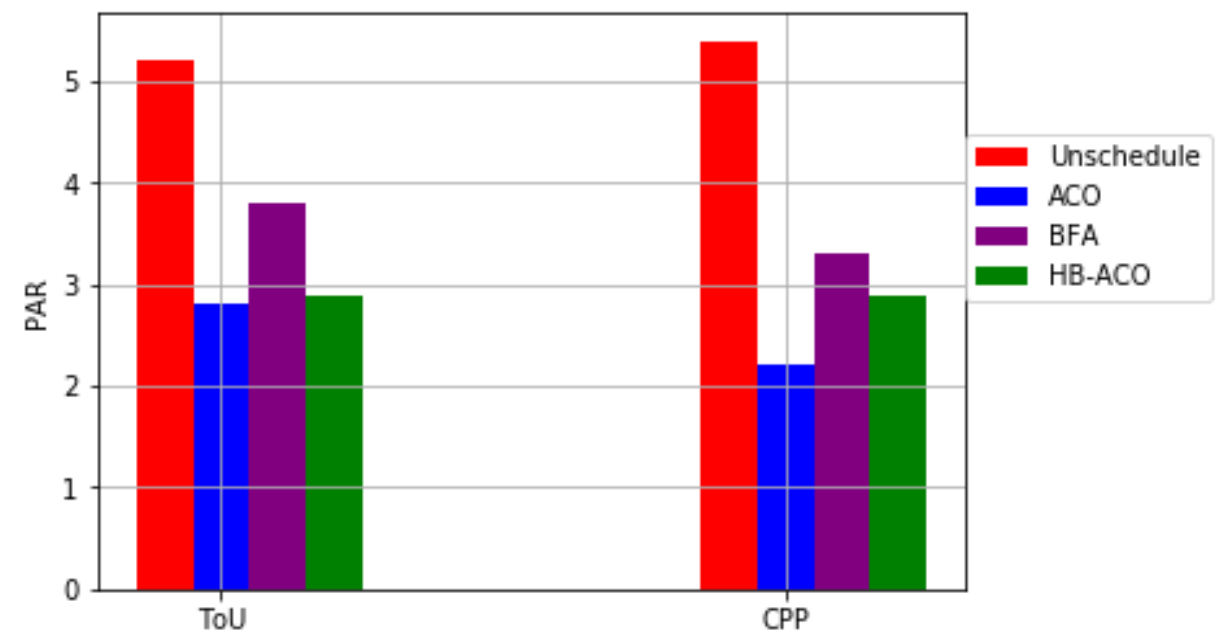

Fig. 10. PAR for proposed HB-ACO and adopted ACO and BFA approaches with coordination 


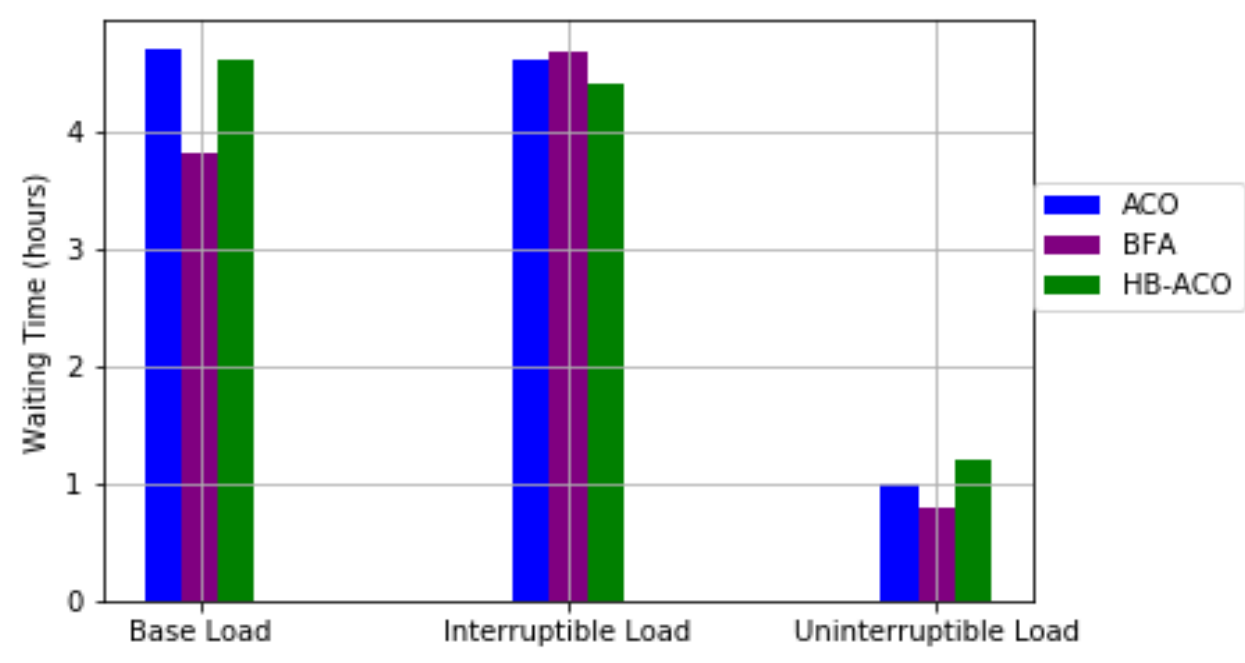

(a) ToU

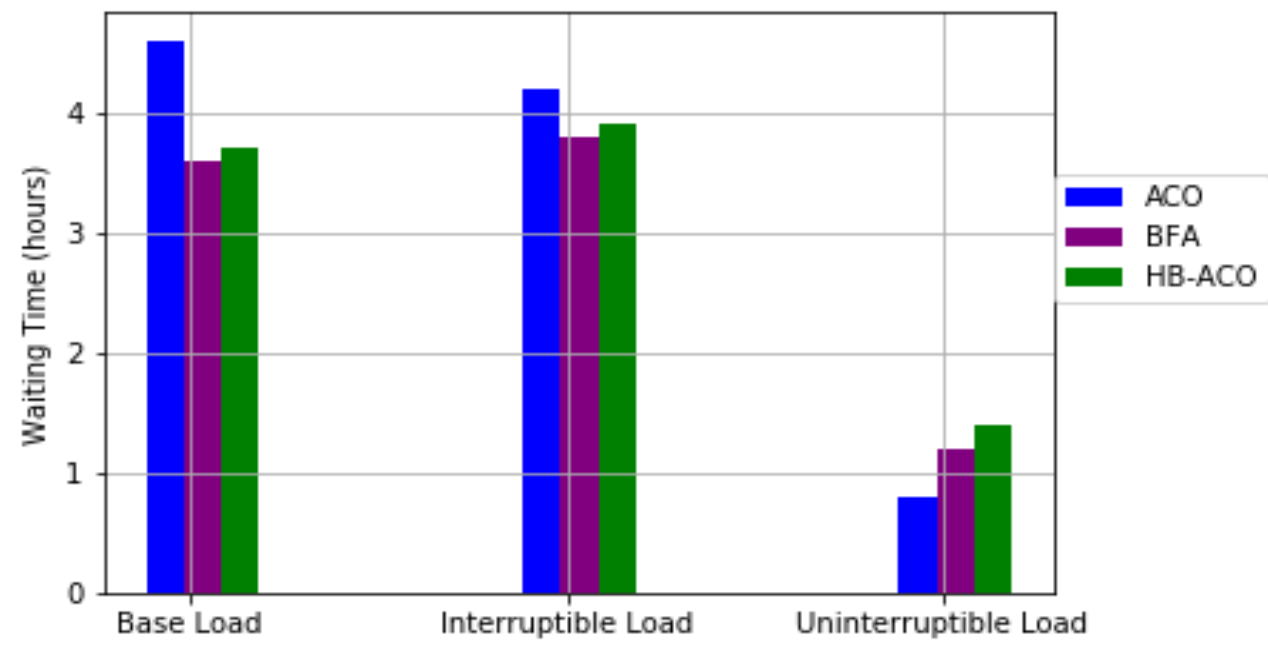

(b) CPP

Fig. 11. Waiting time of appliance before coordination 


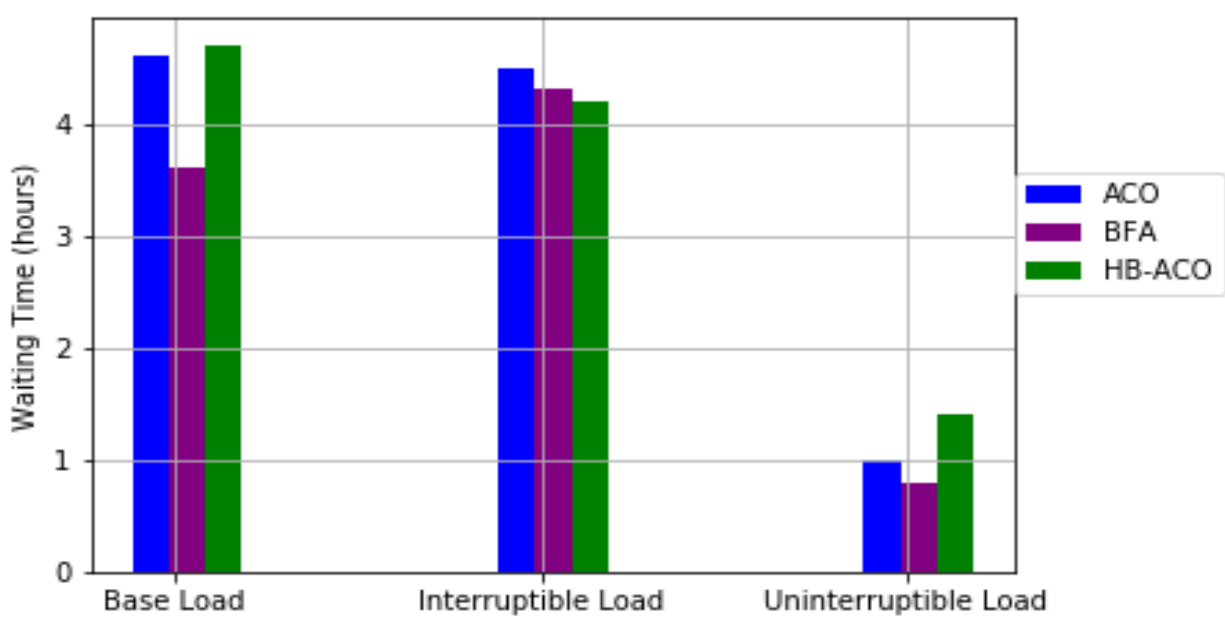

(a) ToU

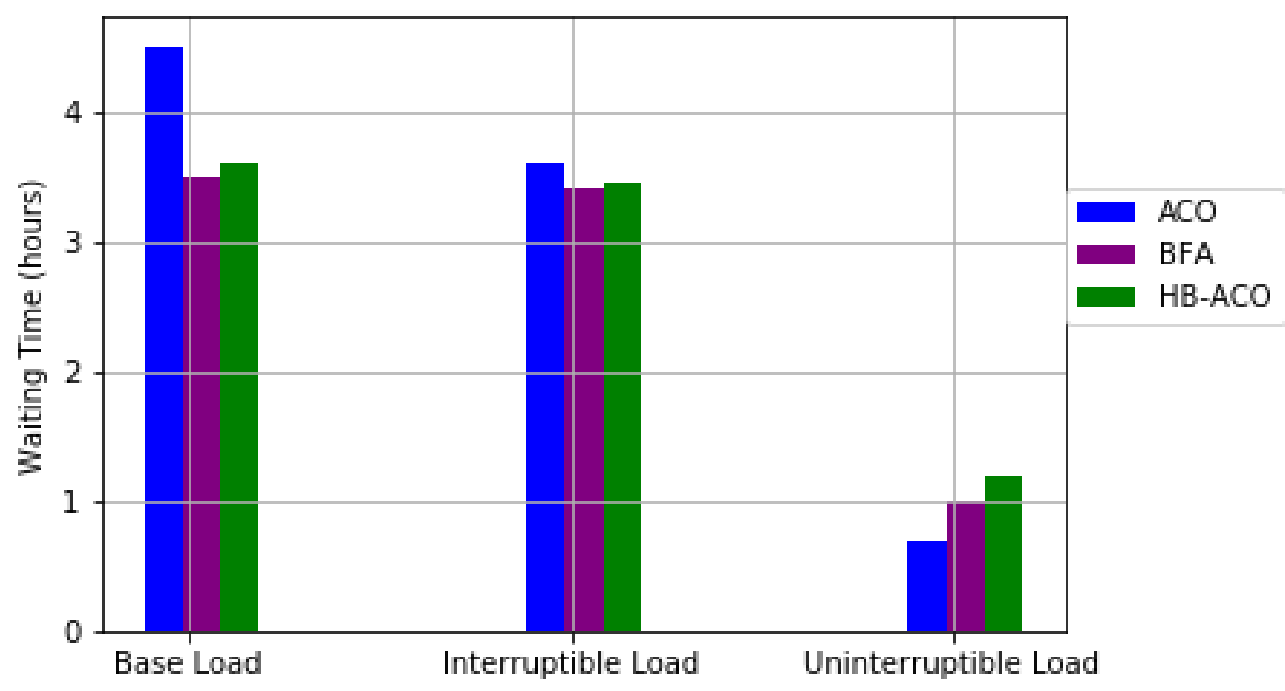

(b) CPP

Fig. 12. Waiting time of appliances after coordination

Table 5. After effect of coordination on different parameters

\begin{tabular}{|l|l|l|l|}
\hline \multirow{2}{*}{ Tariff } & ACO & BFA & HB-ACO \\
\cline { 2 - 4 } & \multicolumn{3}{|c|}{ Cost } \\
\hline ToU & $4 \%$ decrease & $5 \%$ decrease & $6 \%$ decrease \\
\hline CPP & $7 \%$ decrease & $8 \%$ decrease & $9 \%$ decrease \\
\hline & \multicolumn{3}{|c|}{ PAR } \\
\hline ToU & $2 \%$ increase & $4 \%$ increase & $8 \%$ increase \\
\hline CPP & $15 \%$ increase & $12 \%$ increase & $12 \%$ increase \\
\hline & \multicolumn{3}{|c|}{ Waiting Time } \\
\hline ToU & $12 \%$ decrease & $24 \%$ decrease & $16 \%$ decrease \\
\hline CPP & $16 \%$ decrease & $15 \%$ decrease & $8 \%$ decrease \\
\hline
\end{tabular}




\section{Section VI. Conclusion and Future Work}

In this research HEMS is propose to shift electricity load in a single home having multiple appliances. A hybrid algorithm HB-ACO is used for scheduling home appliances on day-ahead basis, for real time scheduling when interrupt occur by consumer to turn ON some other home appliance, we consider this is a knapsack problem and solve it through ACO. To evaluate the performance of proposed algorithm two pricing scheme ToU and CPP are used. For efficiency result of proposed algorithm is compare with ACO and BFA. From result it shows that $48 \%$ electricity cost and $38 \%$ PAR is reduce.

Appliances scheduling is a challenging task because different user have different behavior of consumption electricity. There always exist tradeoff between different parameters like electricity cost, peak to average ratio and user comfort. Opportunity always exist to improve search efficiency to further reduce load of electricity with maximum user comfort.

\section{Section VII. Compliance with Ethical Standards}

Disclosure of potential conflicts of interest: No conflicts of interest between the authors.

Research involving Human Participants and/or Animals: No Human participant and/or Animals involved in the research.

Informed consent: N/A

Funding details: This research work is not funded.

Authorship contributions: Authors contributed as following:

Fakhri Alam Khan: Idea generation, Proposed Model, Evaluation framework

Kifayat Ulaah: realization of Idea, identification of objective, implementation of the algorithm

Atta ur Rahman: Econometric model proposal, evaluations design, discussions and interpretations of the results

Sajid Anwar: Proposed framework, designing literature review, results discussion

\section{REFERENCES:}

[1] Gul, M. S., \& Patidar, S. (2015). Understanding the energy consumption and occupancy of a multipurpose academic building. Energy and Buildings, 87, 155-165.

[2] A. Abdollahi, M. P. Moghaddam, M. Rashidinejad, and M. K. Sheikh-el-Eslami, "Investigation of economic and environmental-driven demand response measures incorporating UC," IEEE Trans. Smart Grid, vol. 3, no. 1, pp. 12-25, 2012.

[3] Davito, B., Tai, H., \& Uhlaner, R. (2010). The smart grid and the promise of demand-side management. McKinsey on Smart Grid, 3, 8-44. 
[4] L. Gelazanskas and K. A. Gamage, “Demand side management in smart grid: A review and proposals for future direction," Sustain. Cities Soc., vol. 11, pp. 22_30, Feb. 2014.

[5] Rahim, M. H., Khalid, A., Javaid, N., Alhussein, M., Aurangzeb, K., and Khan, Z. A. (2018a). Energy e_cient smart buildings using coordination among appliances generating large data. IEEE Access, 6:34670\{34690.

[6] Khalid, A., Javaid, N., Guizani, M., Alhussein, M., Aurangzeb, K., and Ilahi, M. (2018). Towards dynamic coordination among home appliances using multi-objective energy optimization for demand side management in smart buildings. IEEE Access, 6:1950919529.

[7] Ahmad, A., Khan, A., Javaid, N., Majid Hussain, H., Abdul, W., Almogren, A., Alamri, A., and Azim Niaz, I. (2017). An optimized home energy management system with integrated renewable energy and storage resources. Energies.

[8] Rahim, S., Javaid, N., Ahmad, A., Khan, S. A., Khan, Z. A., Alrajeh, N., and Qasim, U. (2016). Exploiting heuristic algorithms to e_ciently utilize energy management controllers with renewable energy sources. Energy and Buildings.

[9] Naz, M., Iqbal, Z., Javaid, N., Wadood, A., Khan, Z. A., Almogren, A., and Alamri, A. (2018). E_cient power scheduling in smart homes using hybrid grey wolf di_erential evolution optimization technique with real time and critical peak pricing schemes. Energies.

[10] Son YS and Moon KD. Home energy management system based on power line communication. IEEE Transactions on Consumer Electronics, Aug 2010, Pages 1380-1386, Print ISSN: 0098-3063 Electronic ISSN: 1558-4127, DOI: 10.1109/TCE.2010.5606273.

[11] Dae-Man Han, Jae-Hyun Lim, "Design and Implementation of Smart Home Energy Management Systems based on ZigBee" IEEE Transactions on Consumer Electronics, 28 October 2010, DOI: 10.1109/TCE.2010.5606278, pages 1117-1125, Print ISSN: 0098-3063

[12] Costanzo, G. T., Zhu, G., Anjos, M. F., \& Savard, G. (2012). A System Architecture for Autonomous Demand Side Load Management in Smart Buildings. IEEE Transactions on Smart Grid, 3(4), 2157-2165. doi:10.1109/tsg.2012.2217358

[13] Keerthisinghe, C., Verbic, G., \& Chapman, A. C. (2018). A Fast Technique for Smart Home Management: ADP With Temporal Difference Learning. IEEE Transactions on Smart Grid, 9(4), 3291-3303. doi:10.1109/tsg.2016.2629470.

[14] Miadreza Shafie-khah, Pierluigi Siano "A Stochastic Home Energy Management System considering Satisfaction Cost and Response Fatigue" IEEE Transactions on Industrial Informatics 19 July 2017, DOI: 10.1109/TII.2017.2728803, Page(s) 629-638, Print ISSN: 1551-3203 Electronic ISSN: 1941-0050

[15] Marco Jahn, Marc Jentsch, Christian R. Prause, Ferry Pramudianto, Amro Al-Akkad, Ren'e Reiners "The Energy Aware Smart Home" IEEE 10 June 2010, 5th International Conference on Future Information Technology, DOI: 10.1109/FUTURETECH.2010.5482712, Print ISSN: 2159-7006 Electronic ISSN: 2159-7014

[16] M Killian, M Zauner, M Kozek “Comprehensive smart home energy management system using mixed-integer quadratic-programming” ELSEVIER, Volume 222, 15 July 2018, Pages 662-672, DOI: 10.1016/j.apenergy.2018.03.179 .

[17] Qinran Hu, Fangxing Li "Hardware Design of Smart Home Energy Management System with Dynamic Price Response" IEEE Transaction on Smart Grid Dec 2013, DOI: 10.1109/TSG.2013.2258181, Page(s) 1878-1887, Print ISSN: 1949-3053 Electronic ISSN: 1949-3061 [18] Siyun Chen, Ting Liu, Feng Gao, Jianting Ji, Zhanbo Xu, Buyue Qian, Hongyu Wu, Xiaohong Guan "Butler, Not Servant: A Human-Centric Smart Home Energy Management System" IEEE Communications Magazine 03 February 2017, DOI: 10.1109/MCOM.2017.1600699CM , Page(s) 27 33, Print ISSN: 0163-6804. 
[19] W. Li, T. Logenthiran, W. L. Woo "Intelligent multi-agent system for smart home energy management" 2015 IEEE Innovative Smart Grid Technologies - Asia (ISGT ASIA), DOI: 10.1109/ISGT-Asia.2015.7386985, Electronic ISSN: 2378-8542

[20] Ting Zhu, Aditya Mishra, David Irwin, Navin Sharma, Prashant Shenoy, Don Towsley "The case for efficient renewable energy management in smart homes" Proceedings of the Third ACM Workshop on Embedded Sensing Systems for Energy-Efficiency in Buildings Seattle, Washington November 01 - 01, 2011 ACM New York, NY, USA @2011, DOI: 10.1145/2434020.2434042, Pages 67-72.

[21] Amjad Anvari-Moghaddam, Hassan Monsef, Ashkan Rahimi-Kian "Optimal Smart Home Energy Management Considering Energy Saving and a Comfortable Lifestyle" IEEE Transaction on Smart Grid January 2015, DOI: 10.1109/TSG.2014.2349352, Page(s) 324- 332, Print ISSN: 1949-3053 Electronic ISSN: 1949-3061

[22] Bin Zhou, WentaoLi, KaWingChan, YijiaCao, YonghongKuang, XiLiu, Xiong Wang "Smart home energy management systems: Concept, configurations, and scheduling strategies" ELSEVIER 13 March 2016, DOI: 10.1016/j.rser.2016.03.047, Page(s) 30-40

[23] Rahim, M. H., Khalid, A., Javaid, N., Alhussein, M., Aurangzeb, K., \& Khan, Z. A. (2018). Energy Efficient Smart Buildings Using Coordination Among Appliances Generating Large Data. IEEE Access, 6, 34670-34690. doi:10.1109/access.2018.2805849

[24] Rahim, S., Javaid, N., Ahmad, A., Khan, S. A., Khan, Z. A., Alrajeh, N., \& Qasim, U. (2016). Exploiting heuristic algorithms to efficiently utilize energy management controllers with renewable energy sources. Energy and Buildings, 129, 452-470. doi:10.1016/j.enbuild.2016.08.008

[25] Hadis Pourasghar, Hossein javadi "An efficient home energy management system for automated residential demand response" EEEIC November 2013, DOI: 10.1109/EEEIC-2.2013.6737927

[26] A Khalid, N Javaid, M Guizani, M Alhussein, Khursheed Aurangzeb, Manzoor Ilahi "Towards Dynamic Coordination Among Home Appliances Using Multi-Objective Energy Optimization for Demand Side Management in Smart Buildings" IEEE Access 09 January 2018, DOI: 10.1109/ACCESS.2018.2791546, Pages 19509-19529, Electronic ISSN: 2169-3536

[27] Adnan Ahmad, Asif Khan, Nadeem Javaid, Hafiz Majid Hussain, Wadood Abdul, Ahmad Almogren, Atif Alamri, Iftikhar Azim Niaz “An Optimized Home Energy Management System with Integrated Renewable Energy and Storage Resources" Energies 2017, 10(4), 549; DOI :10.3390/en10040549

[28] M Killian, M Zauner, M Kozek "Comprehensive smart home energy management system using mixed-integer quadratic-programming” ELSEVIER, Volume 222, 15 July 2018, Pages 662-672, DOI: 10.1016/j.apenergy.2018.03.179 .

[29] Rahim, M., Khalid, A., Javaid, N., Ashraf, M., Aurangzeb, K., \& Altamrah, A. (2018). Exploiting Game Theoretic Based Coordination Among Appliances in Smart Homes for Efficient Energy Utilization. Energies, 11(6), 1426. doi:10.3390/en11061426

[30] A Lorestani, SS Aghaee "Energy management in smart home including PV panel, battery, electric heater with integration of plug-in electric vehicle" IEEE, 2017 Smart Grid Conference (SGC), DOI: 10.1109/SGC.2017.8308855, Electronic ISSN: 2572-6927

[31] Hafiz Majid Hussain, Nadeem Javaid, Sohail Iqbal, Qadeer U1 Hasan ,Khursheed Aurangzeb and Musaed Alhussein “An Efficient Demand Side Management System with a New Optimized Home Energy Management Controller in Smart Grid" Energies, 12 January 2018. https://doi.org/10.3390/en11010190 
[32] Aslam, S., Iqbal, Z., Javaid, N., Khan, Z., Aurangzeb, K., \& Haider, S. (2017). Towards Efficient Energy Management of Smart Buildings Exploiting Heuristic Optimization with Real Time and Critical Peak Pricing Schemes. Energies, 10(12), 2065. doi:10.3390/en10122065

[33] M. Dorigo, M. Birattari, T. Stutzle, Ant colony optimization, IEEE Computational Intelligence Magazine 1(4) (2006) 28-39.

[34] K. M. Passino, 'Biomimicry of bacterial foraging for distributed optimization and control," IEEE Control Syst., vol. 22, no. 3, pp. 52_67, Jun. 2002.

[35] Qayyum, F. A., Naeem, M., Khwaja, A. S., Anpalagan, A., Guan, L., and Venkatesh, B. (2015). Appliance scheduling optimization in smart home networks. IEEE Access, 3:2176\{ 2190.

[36] Cort_es-Arcos, T., Bernal-Agust_n, J. L., Dufo-Lopez, R., Lujano-Rojas, J. M., and Contreras, J. (2017). Multi-objective demand response to real-time prices (rtp) using a task scheduling methodology. Energy, 138:19\{31.

[37] Muralitharan, K., Sakthivel, R., and Shi, Y. (2016). Multiobjective optimization technique for demand side management with load balancing approach in smart grid. Neurocomputing,177:110-119. 